Article

\title{
Organo-Modified Vermiculite: Preparation, Characterization, and Sorption of Arsenic Compounds
}

\author{
Magdalena Tuchowska ${ }^{\circledR}$, Magdalena Wołowiec, Agnieszka Solińska, Anita Kościelniak \\ and Tomasz Bajda *(D) \\ Faculty of Geology, Geophysics and Environmental Protection, AGH University of Science and Technology, \\ al. A. Mickiewicza 30, 30-059 Krakow, Poland \\ * Correspondence: bajda@agh.edu.pl; Tel.: +48-12-617-52-32
}

Received: 13 June 2019; Accepted: 8 August 2019; Published: 12 August 2019

check for updates

\begin{abstract}
Among the various technologies tested for removing the anionic species resulting from arsenic contamination, sorption methods have received unflagging interest. Being potential sorbent materials, clay minerals modified by cationic surfactants are often examined for this purpose. Among the clay minerals tested, information regarding sorption properties of expanded vermiculite modified with surfactants is scarce. Therefore, the present study aims to prepare organo-vermiculites modified with hexadecyltrimethylammonium (HDTMA) and benzyldimethylhexadecylammonium (HDBA) at surfactant concentrations of $0.5,1.0$, and 2.0 cation exchange capacity. Modified sorbents were identified and characterized using the analytical methods that can determine phase composition and textural properties of the samples. The sorption of $\mathrm{As}(\mathrm{III})$ and $\mathrm{As}(\mathrm{V})$ as a function of initial $\mathrm{pH}$ value, initial concentration of As(III, V), and initial dosage of sorbent was investigated. The results show that HDTMA and HDBA affect the properties of raw vermiculite. For instance, increase in the concentration of surfactants is often accompanied by a change in interlayer space or textural properties of vermiculite. It was observed that tested organo-minerals adsorbed $\mathrm{As}(\mathrm{V})$ to a greater extent compared to As(III). Various analytical studies were carried out and the results revealed the successful synthesis of organo-vermiculite. Moreover, the study also showed that the structure of organo-vermiculite has a significant impact on the uptake of $\mathrm{As}(\mathrm{III})$ and $\mathrm{As}(\mathrm{V})$ anions.
\end{abstract}

Keywords: anionic species of arsenic; HDTMA; HDBA; sorption; organo-vermiculite

\section{Introduction}

Arsenic (As) is a highly toxic element to both humans and animals and one of the most hazardous substances in the environment [1]. Arsenic exists primarily in two oxidation forms: arsenate $(\mathrm{As}(\mathrm{V}))$ and arsenite $(\mathrm{As}(\mathrm{III}))$. As(III) is more toxic than $\mathrm{As}(\mathrm{V})$ and pose a greater threat to society due to its higher solubility in aqueous solutions [2]. Contamination of water with arsenic compounds is one of the most significant scientific challenges. Natural activities that increase As concentration in aqueous systems are weathering, volcanic emissions, erosion of soils/rock, and biological metabolism [3,4], while mining wastes, ceramic manufacturing industries, agricultural chemicals, petroleum refining, coal fly ash, and military operations contribute to the anthropogenic sources of arsenic [5,6]. Hence, rapidly increasing urbanization and industrialization activities considerably enhance the degree of arsenic pollution. Annually, more than 60,000 tons of arsenic is emitted into the environment [5]. Standard provisional guideline of the World Health Organization (WHO) for drinking water is $10 \mu \mathrm{g} / \mathrm{L}$ [7]. Millions of people are being exposed to the harmful effects of arsenic. Exposure to water contaminated with arsenic results in various health problems such as diabetes, circulatory disorders, neurological complications, hepatic and renal dysfunction, skin cancer, and gangrene of the limbs [8]. 
In the last decades, various technologies for removing As from contaminated water have been investigated, such as oxidation, coagulation, ion exchange, precipitation, membrane filtration, biological treatment, and sorption [9-11]. However, most of these methods have drawbacks, including high costs, deficient removal, generation of waste products, or high reagent and energy requirement. Among the methods mentioned earlier, adsorption seems to be the most effective method [1,12]. For removal by adsorption technique, activated carbon, metal-organic frameworks, zeolites, bog iron ores, water treatment residuals, and activated alumina have been proven to be promising adsorbents for arsenic removal [13-17].

Clay minerals are low-cost and nontoxic sorbents. Raw clays are able to sorb cations owing to their negatively charged surface; however, they display low sorption efficiency for negatively charged contaminants such as arsenic [18]. Nevertheless, clays can be chemically modified by organic surfactants, which change the charge on the clay surface from negative to positive [19]. The organo-clays are hydrophobic materials that can effectively sorb anions and organic compounds. Modified kaolinite, montmorillonite, and illite are the most popular clay minerals that are used as sorbents [20-22]. However, only a few studies have focused on using organo-vermiculites to sorb anions [23,24].

Vermiculite is a 2:1 phyllosilicate mineral having a sandwiched structure with two tetrahedral sheets coupled with one octahedral sheet [25]. Vermiculite has a large internal surface, high cation exchange capacity (CEC), and high negative charge on the silicate layers [26,27]. Therefore, addition of a surfactant is necessary for the sorption of anions. For the purpose of this study, the authors chose two surface active agents: hexadecyltrimethylammonium bromide (HDTMA-Br) and benzyldimethylhexadecylammonium chloride (HDBA-Cl). HDTMA-Br is most commonly used [28,29], and the HDTMA molecule consists of 16 carbon atoms and constitutes the chain where hydrophilic head is attached. Organo-vermiculite modified with HDTMA has been proved to be an effective sorbent for organic compounds and anions [30,31]. HDBA-Cl is less commonly used and is an amphiphilic surfactant with one hydrophilic group and two hydrophobic groups [32].

The primary objective of this study was to prepare quaternary ammonium salt-modified organo-vermiculites (HDTMA-Br and HDBA-Cl) at surfactant concentrations of 0.5, 1.0, and 2.0 CEC. Organo-vermiculites were characterized by X-ray diffraction (XRD), Fourier-transform infrared spectroscopy (FTIR), scanning electron microscopy (SEM), and thermogravimetric and differential thermal analysis (TG/DTA). The textural parameters were also evaluated. The secondary objective was to test the potential adsorption capacity for As(III) and As(V) ions. Assessment was done to determine the possibility of the binding of arsenic anions onto organo-vermiculites, which in turn will allow to evaluate whether this material can be successfully used in installations for water and wastewater treatment.

\section{Materials and Methods}

\subsection{Materials}

Raw, expanded vermiculite (VER) with a size fraction of 0.25-1 mm, purchased from Kazakhstan's manufacturer AVENUE (Shymkent, Kazakstan), was investigated in this study. Prior to organic modification using HDTMA-Br and HDBA-Cl, the CEC of vermiculite was determined. This procedure allows to estimate the number of cationic surfactant molecules which are attached to form a monolayer (corresponding to 1.0 CEC) on the surface of vermiculite and in the interlayer space [33]. Thus, $1 \mathrm{~g}$ of VER was dispersed in $100 \mathrm{~mL}$ of double-distilled water and mixed by using a magnetic stirrer at $80{ }^{\circ} \mathrm{C}$ for $3 \mathrm{~h}$. Subsequently, $1 \mathrm{~g}$ of dissolved HDTMA-Br was added to this suspension and stirred additionally for $24 \mathrm{~h}$. After this period, another portion of dissolved $1 \mathrm{~g}$ HDTMA-Br was added and mixed for $5 \mathrm{~h}$. Then, the modified material was centrifuged at $4500 \mathrm{rpm}$ for $5 \mathrm{~min}$ and washed with hot double-distilled water as long as reaction for bromides $\left(\mathrm{Br}^{-}\right)$, determined by applying $\mathrm{AgNO}_{3}$, was negative. Finally, the material thus obtained was washed with hot ethanol and dried at $105^{\circ} \mathrm{C}$ for 24 h. An automatic analyzer CHNS Vario EL III (Elementar Analysensysteme GmbH, Langenselbold, 
Germany) was used to measure the content of nitrogen $(\mathrm{N})$, carbon $(\mathrm{C})$, and hydrogen $(\mathrm{H})$ in VER before and after HDTMA treatment. Based on the differences between the amounts of N, C, and $\mathrm{H}$ elements in HDTMA-modified vermiculite and VER, CEC could be calculated. The results obtained indicate that 1.0 CEC of vermiculite is equal to $89 \mathrm{meq} / 100 \mathrm{~g}$ and corresponds to sorption of $25.4 \mathrm{~g}$ of HDTMA or 32.1g of HDBA/100 $\mathrm{g}$ of VER.

After determining the CEC value, the next step was to prepare organo-sorbents (six samples): HDTMA-vermiculite with 0.5, 1.0, and 2.0 CEC and HDBA-vermiculite with 0.5, 1.0, and 2.0 CEC. The content in each of the six beakers, containing $30 \mathrm{~g}$ of VER and $600 \mathrm{~mL}$ of double-distilled water, was mixed by using a magnetic stirrer at $65^{\circ} \mathrm{C}$. Then, dissolved HDTMA-Br or HDBA-Cl solution containing an appropriate amount of surfactant (Table 1 ) was added to suspensions and further stirred at $65{ }^{\circ} \mathrm{C}$ for $6 \mathrm{~h}$. After this period, unwashed, modified samples were placed in a heated bath and left to dry for $24 \mathrm{~h}$. Finally, the organo-vermiculites were homogenized in an agate mortar. The six organo-sorbent samples thus prepared were named as follows:

- HDTMA-modified VER at the concentrations of 0.5, 1.0, and 2.0 CEC: 0.5 HDTMA, 1.0 HDTMA, and 2.0 HDTMA, respectively.

- HDBA-modified VER at the concentrations of 0.5, 1.0, and 2.0 CEC: 0.5 HDBA, 1.0 HDBA, and 2.0 HDBA, respectively.

Table 1. The amount of dissolved cationic surfactants $(\mathrm{g})$ required to prepare $30 \mathrm{~g}$ of $0.5,1.0,2.0$ hexadecyltrimethylammonium (HDTMA) and 0.5, 1.0, 2.0 benzyldimethylhexadecylammonium (HDBA).

\begin{tabular}{ccccccc}
\hline Parameter & \multicolumn{3}{c}{ HDTMA } & \multicolumn{3}{c}{ HDBA } \\
\hline Multiple of CEC & 0.5 & 1.0 & 2.0 & 0.5 & 1.0 & 2.0 \\
\hline Amount of organic salt $(\mathrm{g})$ & 4.9 & 9.7 & 19.5 & 5.3 & 10.6 & 21.2 \\
\hline
\end{tabular}

\subsection{Sorption Experiments}

The batch experiments to determine $\mathrm{As}(\mathrm{III})$ and $\mathrm{As}(\mathrm{V})$ sorption were carried out at $20 \pm 1{ }^{\circ} \mathrm{C}$. The following reagents were used as the source of arsenic ions: $\mathrm{NaAsO}_{2}$ for $\mathrm{As}$ (III) anions and $\mathrm{Na}_{2} \mathrm{HAsO}_{4} \cdot 7 \mathrm{H}_{2} \mathrm{O}$ for $\mathrm{As}(\mathrm{V})$ anions. All experiments were conducted in duplicates.

The experiments relating to adsorption of $\mathrm{As}(\mathrm{III}) /(\mathrm{V})$ anions were executed in two stages:

- In the first stage, experiments were conducted using VER and all organo-sorbents, i.e., 0.5, 1.0, 2.0 HDTMA and 0.5, 1.0, 2.0 HDBA.

- In the second stage, experiments were conducted using VER, 0.5, 2.0 HDTMA, and 0.5, 2.0 HDBA.

In the first stage, sorption of arsenic oxyanions onto unmodified and modified vermiculite was examined for variable $\mathrm{pH}$ values in the range of 2-12 at the initial concentration of $1.3 \mathrm{mmol}$ of $\mathrm{As}$ (III) or $\mathrm{As}(\mathrm{V}) / \mathrm{L}$. The $\mathrm{pH}$ was adjusted by adding $0.1 \mathrm{M} \mathrm{NaOH}$ and $0.1 \mathrm{M} \mathrm{NHO}_{3}$. In addition, the sorption of arsenic anions was determined for different initial concentrations (0.5-20 mmol/L) of As(III) and As(V) at an initial $\mathrm{pH}$ value of 5 . Therefore, $100 \mathrm{mg}$ of each sample and $5 \mathrm{~mL}$ of As(III) or As(V) solution were taken into $7.5 \mathrm{~mL}$ polypropylene tubes and shaken for $24 \mathrm{~h}$. Afterward, the mixtures were centrifuged at $14,000 \mathrm{rpm}$ for $10 \mathrm{~min}$ and decanted. The $\mathrm{pH}$ value of all the supernatants was measured. In the second stage, the sorption of As(III) and As(V) onto VER and only 0.5, 2.0 HDTMA and 0.5, 2.0 HDBA was measured for the variable sorbent dosage at a range of $10-150 \mathrm{~g} / \mathrm{L}$, at the initial concentration of $5 \mathrm{mmol} \mathrm{As}(\mathrm{III})$ or $\mathrm{As}(\mathrm{V}) / \mathrm{L}$ and initial $\mathrm{pH}$ value equal to 6. Then, $5 \mathrm{~mL}$ of $\mathrm{As}(\mathrm{III})$ or $\mathrm{As}(\mathrm{V})$ solution was mixed with an appropriate portion of samples in $7.5 \mathrm{~mL}$ polypropylene tubes and shaken for $24 \mathrm{~h}$. The sample portions corresponded to 50, 100, 250, 375, 500, and $750 \mathrm{mg}$, respectively. After $24 \mathrm{~h}$, the mixtures were centrifuged at 14,000 rpm for $10 \mathrm{~min}$ and decanted. 
The content of $\mathrm{As}(\mathrm{III})$ and $\mathrm{As}(\mathrm{V})$ in supernatants was measured using atomic absorption spectrometer (Savant AA GBC Scientific Equipment, Braeside, Australia). The adsorption efficiency S (mmol/kg) was calculated as follows:

$$
S=\left(\frac{C_{0}-C_{e q}}{C_{0}}\right)
$$

where $C_{0}$ is the initial $\mathrm{As}(\mathrm{III})$ or $\mathrm{As}(\mathrm{V})$ concentration $(\mathrm{mmol} / \mathrm{L})$ and $C_{e q}$ is the concentration of $\mathrm{As}(\mathrm{III})$ or $\mathrm{As}(\mathrm{V})$ in equilibrium solution $(\mathrm{mmol} / \mathrm{L})$ after sorption.

\subsection{Adsorption Models}

In order to describe the adsorption of $\mathrm{As}(\mathrm{III})$ and $\mathrm{As}(\mathrm{V})$ onto unmodified and modified vermiculite, two well-known models, i.e., Langmuir [34] and Freundlich [35] isotherm models were used (corresponding to Equations (2) and (3), respectively):

$$
\begin{gathered}
n=\frac{K_{L} \times Q \times C_{e q}}{1+K_{L} \times C_{e q}} \\
n=K_{F} \times C_{e q}^{1 / v}
\end{gathered}
$$

where $n$ is the adsorbed amount of $\mathrm{As}(\mathrm{III})$ or $\mathrm{As}(\mathrm{V})$ onto unmodified and modified vermiculite $(\mathrm{mmol} / \mathrm{kg}), C_{e q}$ is the concentration of $\mathrm{As}(\mathrm{III})$ or $\mathrm{As}(\mathrm{V})$ in equilibrium solution $(\mathrm{mmol} / \mathrm{L})$ after sorption, $K_{L}$ is the Langmuir adsorption constant (L/mmol), $Q$ is the maximum adsorption capacity $(\mathrm{mmol} / \mathrm{kg})$, $K_{F}$ is the Freundlich adsorption constant $(\mathrm{mmol} / \mathrm{kg})$, and $v$ is the Freundlich dimensionless constant.

The $K_{L}$ and $K_{F}$ adsorption constants were calculated from linearization of Langmuir (Equation (4)) and Freundlich (Equation (5)) adsorption equations:

$$
\begin{gathered}
\frac{C_{e q}}{n}=\frac{1}{K_{L} \times Q}+\frac{C_{e q}}{Q} \\
\log n=\log K_{F}+\frac{1}{v} \times \log C_{e q}
\end{gathered}
$$

\subsection{Analytical Methods}

The mineral composition of the investigated samples was obtained via powder XRD, using SmartLab RIGAKU diffractometer (RIGAKU, Tokyo, Japan) with graphite-monochromatized Cu $\mathrm{u}_{\mathrm{K} \alpha}$ radiation, operating at a voltage of $9 \mathrm{kV}$ and measuring step $0.05^{\circ} 2 \theta / 1 \mathrm{~s}$. The XRD patterns were interpreted using XRayan program (Version 4.2.2, "KOMA", Warsaw, Poland). The FTIR spectra were recorded by Nicolet 6700 spectrometer (Fishers, Waltham, MA, USA) using the drift technique (3 wt. \% sample/KBr) with 64 scans at $4 \mathrm{~cm}^{-1}$ resolution in the $4000-400 \mathrm{~cm}^{-1}$ region. Morphology observations of uncoated samples were analyzed by field emission scanning electron microscope (FEI QUANTA 200, Graz, Austria). The $\mathrm{N}_{2}$ adsorption/desorption isotherms were measured at $-196{ }^{\circ} \mathrm{C}$ using ASAP 2020 apparatus (Micromeritics, Norcross, GA, USA). Prior to measurements, samples were outgassed for $24 \mathrm{~h}$ at $100{ }^{\circ} \mathrm{C}$. Based on the data obtained from $\mathrm{N}_{2}$ isotherms, specific surface area $\left(S_{B E T}\right)$ was calculated by applying Brunauer-Emmett-Teller (BET) equation, while Barrett-Joyner-Halenda (BJH) method was used to determine the pore size distribution. The thermal analysis (DTA/TG) coupled with the measurement of evolved gases composition was performed by using Netzsch STA 449 F3 Jupiter apparatus (Netzsch, Chennai, India). Samples were heated at a temperature range of 30-1000 ${ }^{\circ} \mathrm{C}$ at a heating rate of $10^{\circ} \mathrm{C} / \mathrm{min}$. Simultaneously the evolved gaseous products will be analyzed with the Aeolos QMS 403 C mass spectrometer (Netzsch, Chennai, India). 


\section{Results}

\subsection{Modification of Vermiculite with HDTMA and HDBA}

\subsubsection{XRD}

XRD patterns of HDTMA, VER, 0.5 and 2.0 HDTMA are presented in Figure 1. The basal VER's reflection at $14.31 \AA$ suggests that hydrated magnesium cations are located in its interlayer space (Figure 1b). Analysis of vermiculite after modification with HDTMA reveals significant changes in relation to VER. The patterns display two characteristic reflections at 38-39 $\AA$ and 17-19 $\AA$ [18]. In the case of reflection at 38-39 $\AA$, the intensity of reflection slightly increased with an increase in the added surfactant concentration, whereas for the reflection at $14 \AA$, the intensity of reflection decreased in case of 2.0 HDTMA (Figure 1c,d). This finding supports the fact that VER is almost fully saturated with HDTMA at 2.0 CEC and that the basal reflection of vermiculite disappears completely [36]. Additionally, most of the VER reflections disappear completely for 2.0 HDTMA. Reflections at 38-39 $\AA$ and 17-19 $\AA$ are more rounded in the case of 0.5 HDTMA than for modifications involving 2.0 HDTMA. Figure 1a represents the XRD pattern of HDTMA-Br. It can be noted that there are no reflections from the salt in 0.5 and 2.0 HDTMA samples, confirming that there is no physical mixture of the vermiculite and surfactant. Hence, the modification has been carried out correctly. The results, which coincide with others described in the literature, confirm that the modification of vermiculite using HDTMA was successful. Various mineral-organic complexes capable of adsorbing different anions have been designed $[18,24,30]$.

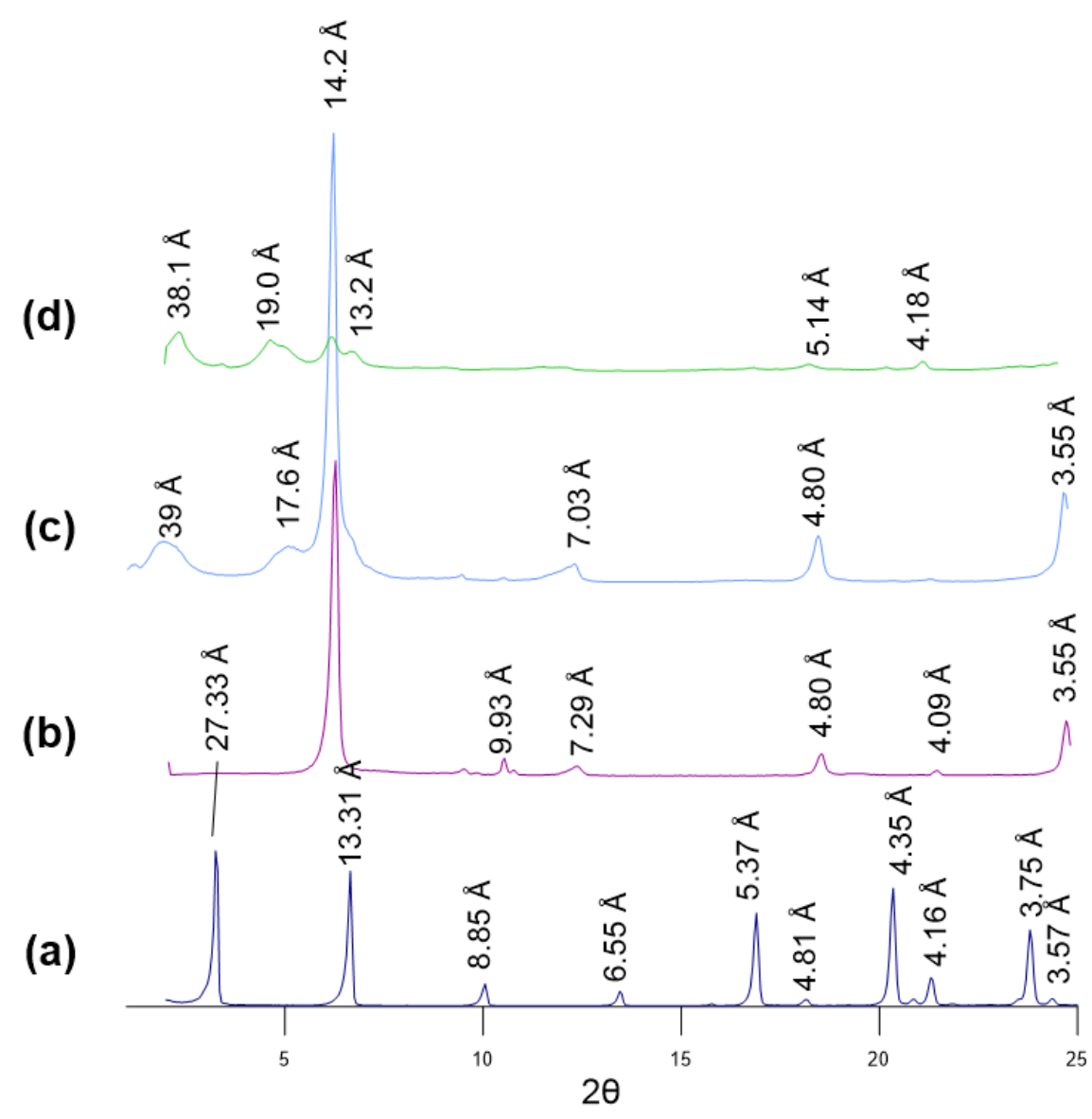

Figure 1. X-ray diffraction patterns of: (a) HDTMA, (b) raw, expanded vermiculite (VER), (c) 0.5 HDTMA, and (d) 2.0 HDTMA. 
XRD patterns of HDBA, VER, and 0.5 and 2.0 HDBA are presented in Figure 2. The basic change in relation to vermiculite is related to the shift of the diagnostic reflection toward a higher d-value, which results directly from an increase in the interplanar distance of this mineral (Figure $2 b-d$ ). Similarly to the VER modified with HDTMA, a higher intensity of reflection originating from a lower modification was observed, which indicates the disappearance of reflections from vermiculite. Figure 2a shows the HDBA pattern, which shows that as before, the reflections characteristic of HDBA are not visible in the diffraction patterns of 0.5 and $2.0 \mathrm{HDBA}$, indicating that the modification proceeded completely.

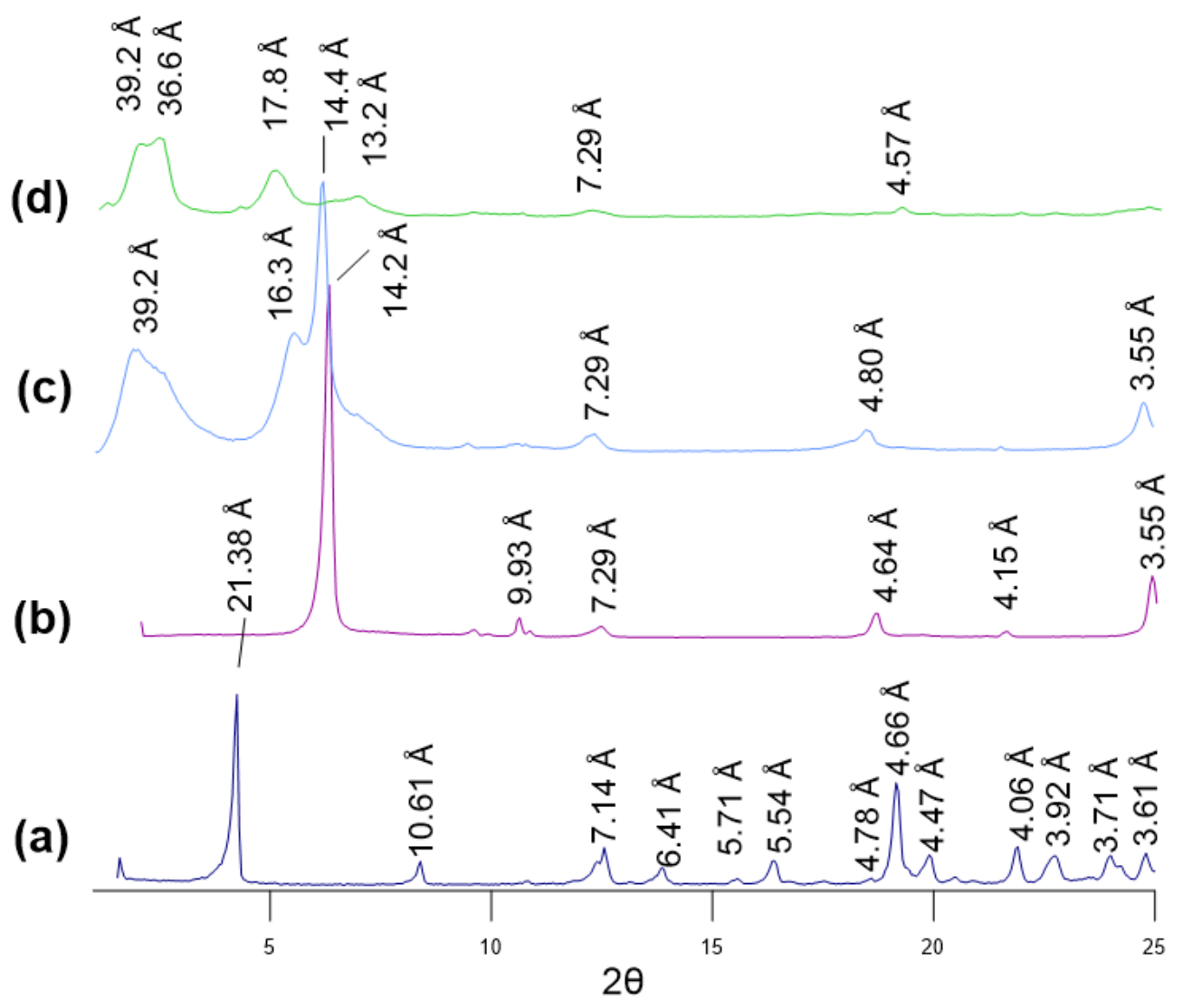

Figure 2. X-ray diffraction patterns of: (a) HDBA, (b) VER, (c) 0.5 HDBA, and (d) 2.0 HDBA.

\subsubsection{FTIR}

The results of FTIR analysis for VER, 0.5 and 2.0 HDTMA, and 0.5 and 2.0 HDBA are presented in Figure 3. The diagnostic bands characteristic of the vermiculite, related to vibrations at tetrahedral and octahedral sheets (as well as for the other layered silicates), are observed at the range of $400-1000 \mathrm{~cm}^{-1}[37,38]$. The band at $3650 \mathrm{~cm}^{-1}$ is ascribed to vermiculite's structural hydroxyl group. The stretching and deformation vibrations of water molecules are observed at 3410 and $1655 \mathrm{~cm}^{-1}$, respectively. The adsorption of HDTMA on vermiculite in the analyzed samples is evidenced by the presence of additional bands that are derived from vibrations of surfactant molecules (occurring at the positions 2918, 2850, 1487, and $1473 \mathrm{~cm}^{-1}$ ), which were found to be absent in VER [39,40]. Bands occurring in the $2920-2850 \mathrm{~cm}^{-1}$ range are the result of symmetrical and asymmetric $\mathrm{C}-\mathrm{H}$ stretching vibrations occurring within the methylene groups of HDTMA $[18,39,41]$. The characteristic bands observed at around $1470 \mathrm{~cm}^{-1}$ are derived from bending vibrations of $\mathrm{C}-\mathrm{H}$ within the methyl groups of the surfactant [26,42-44]. The presence of HDBA was revealed by the presence of bands at the following positions: 2923,2853 , and $1450 \mathrm{~cm}^{-1}$ [45]. Increasing the amount of surfactant caused an increase in the intensity of these bands, while the intensity of bands characteristic of vermiculite decreased. 

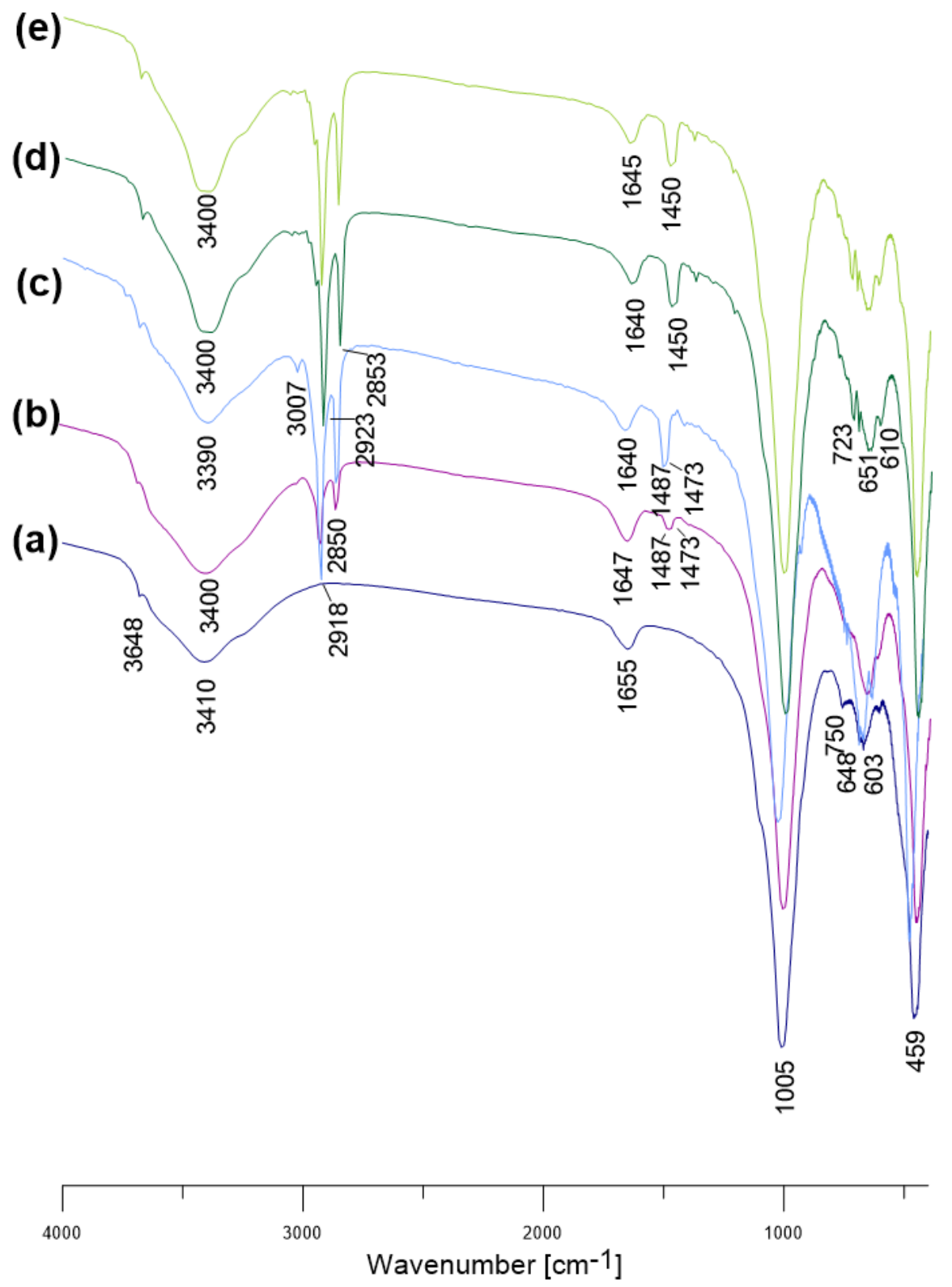

Figure 3. FTIR spectra of: (a) VER, (b) 0.5 HDTMA, (c) 2.0 HDTMA, (d) 0.5 HDBA, and (e) 2.0 HDBA.

The modification of vermiculite did not cause significant changes in the location and intensity of its diagnostic bands. This is due to the fact that the modification occurred only on the surface of the mineral [46]. However, a shift of the bands, originating from the vibrations of the water molecules, toward the lower wavenumbers was observed in relation to the IR spectrum of VER (range: $3410-3390 \mathrm{~cm}^{-1}$; $1655-1647 \mathrm{~cm}^{-1} ; 750-720 \mathrm{~cm}^{-1}$; and $610-600 \mathrm{~cm}^{-1}$ ). The peaks relating to $\mathrm{O}-\mathrm{H}$ stretching vibration and bending vibration also declined [47]. These changes are caused by a decrease in the amount of water in the mineral interlayer space, which is associated with the hydrophobization of its surface and the greater size of the organic cations compared to the inorganic ones originally present in the mineral $[43,46]$.

\subsection{3. $\mathrm{N}_{2}$-BET}

The textural parameters of VER, 0.5, 2.0 HDTMA, and 0.5, 2.0 HDBA have been obtained by the nitrogen adsorption/desorption studies (Figure 4 and Table 2). According to the IUPAC system, a VER has a type IV of isotherms and H4 type of hysteresis loop, which are characteristic of mesoporous 
materials with narrow slit-like pores [48]. The specific surface area $\left(S_{B E T}\right)$ of VER is $7.34 \mathrm{~m}^{2} / \mathrm{g}$. The pore size distribution is relatively varied; however, a pore size greater than $10 \mathrm{~nm}$ dominates (Figure 5). The pores have an average diameter of $10.48 \mathrm{~nm}$.

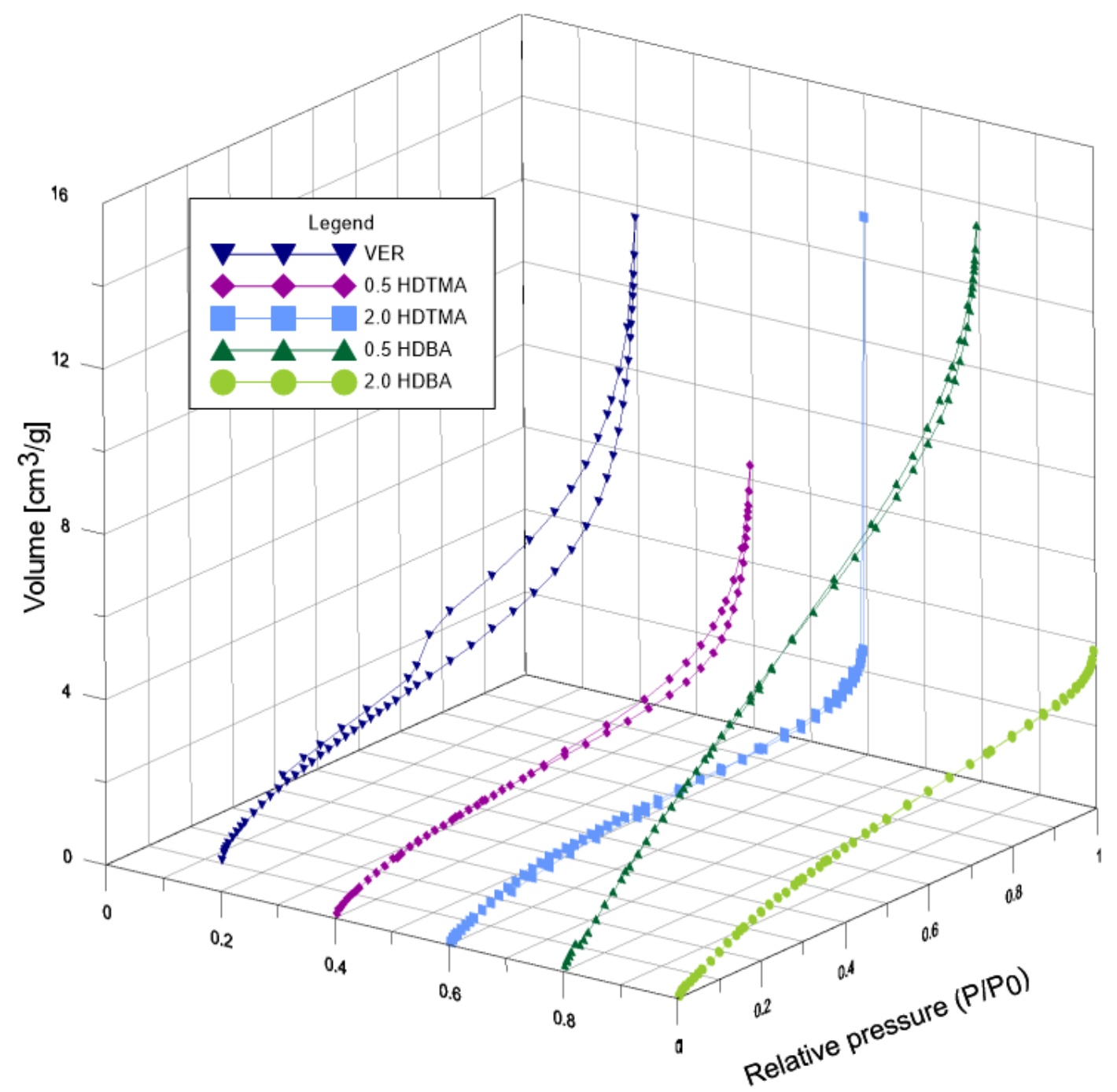

Figure 4. Comparison of $\mathrm{N}_{2}$ adsorption and desorption isotherms at $-196{ }^{\circ} \mathrm{C}$ for $\mathrm{VER}, 0.5$ and 2.0 HDTMA, and 0.5 and 2.0 HDBA.

Table 2. The textural parameters of VER, 0.5 and 2.0 HDTMA, and 0.5 and 2.0 HDBA.

\begin{tabular}{cccc}
\hline Sample & $S_{B E T}\left(\mathbf{m}^{2} / \mathrm{g}\right)$ & $D_{\boldsymbol{p}}(\mathbf{n m})$ & $V_{\text {mes }}\left(\mathrm{cm}^{3} / \mathrm{g}\right)$ \\
\hline VER & 7.34 & 10.48 & 0.0138 \\
\hline 0.5 HDTMA & 3.49 & 14.35 & 0.0070 \\
\hline 2.0 HDTMA & 4.23 & 11.35 & 0.0026 \\
\hline 0.5 HDBA & 15.47 & 5.55 & 0.0175 \\
\hline 2.0 HDBA & 5.93 & 4.66 & 0.0053 \\
\hline
\end{tabular}

Abbreviations: $V_{\text {mes }}$, pore volume (Ø 1.7-300 nm); $D_{p}$, average pore diameter.

Significant changes are observed in the $\mathrm{N}_{2}$-isotherm curves of organo-vermiculates after HDTMA modifications. The results show that isotherms of 0.5, 2.0 HDTMA lay below the VER, corresponding to decreased sorption capacity of $\mathrm{N}_{2}$ (Figure 4) which subsequently results in a decrease in porosity, 
pore volume, and $S_{B E T}$ of modified organo-sorbents. It is a consequence of the uptake of relatively larger HDTMA molecules onto external [49] and internal space of vermiculite which limits access to its pores. Wherein, a reduction of porosity, manifested by decreased pore volume, is more visible for the organo-sorbent samples using the HDTMA concentrations exceeding CEC of vermiculite. Generally, higher loading of vermiculite by HDTMA molecules reduces the porosity of modified sorbents. Additionally, the modification caused a change in the shape of the pores, which is demonstrated by narrowing of the hysteresis loop of 0.5 and 2.0 HDTMA isotherms.

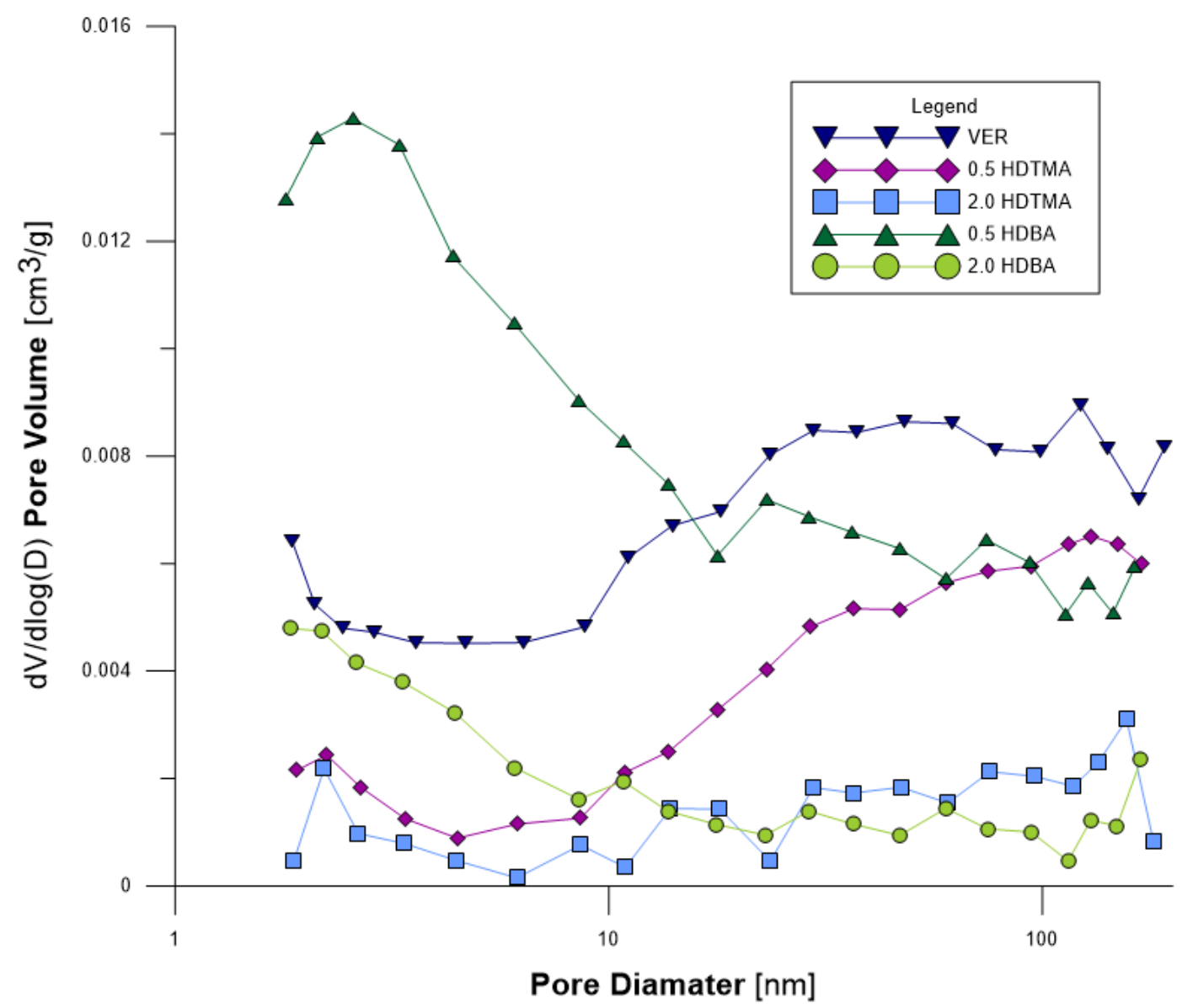

Figure 5. Pore size distribution for VER, 0.5 and 2.0 HDTMA, and 0.5 and 2.0 HDBA.

Analysis of pore size distribution indicates significant differences between 0.5 and 2.0 HDTMA pore diameters in comparison to VER (Figure 5). Attachment of HDTMA molecules onto the surface of vermiculite induces a decrease in the number of small pores, owing to an increase in the average pore size of modified HDTMA vermiculite. Moreover, the curves also show that increasing load of HDTMA also caused a drop in the diameter of large pores $(>10 \mathrm{~nm})$. Nevertheless, the average pore size was higher with reference to VER and equaled $14.35 \mathrm{~nm}$, and was found to be $11.35 \mathrm{~nm}$ for 0.5 and 2.0 HDTMA.

The results of nitrogen adsorption/desorption studies for 0.5 and 2.0 HDBA are more complicated. In the case of 2.0 HDBA, a decrease in the $S_{B E T}\left(5.93 \mathrm{~m}^{2} / \mathrm{g}\right)$ value and its porosity has been observed, which is manifested by the location of 2.0 HDBA's adsorption/desorption isotherm curve below the isotherm curve of VER (Figure 4). Similar to HDTMA modification, increasing amounts of HDBA-adsorbed molecules limit the access to vermiculite's pores, thus decreasing its porosity. On the other hand, 0.5 HDBA isotherms line above the adsorption/desorption curve of VER, indicating an increase in the porosity of $0.5 \mathrm{HDBA}$. Its specific surface area $\left(S_{B E T}\right)$ also increases by two times when compared to the $S_{B E T}$ of VER (Table 2). Enhanced porosity could be related to the specific arrangement 
of HDBA molecules, particularly in the internal space of the vermiculite. The hysteresis loops of both 0.5 and 2.0 HDBA isotherms are almost unnoticeable when compared to VER, suggesting that modification changes the shape of the pores of organo-vermiculites.

The curves representing the pore size distribution of 0.5 and 2.0 HDBA samples reveal that regardless of the modification by the sorbents, the HDBA-vermiculite complexes predominantly contain small pores $(<10 \mathrm{~nm})$ (Figure 5), resulting in decreased average pore diameter (Table 2). However, the number of small pores was greater in 0.5 HDBA sample than in 2.0 HDBA sample and greater than in VER. Hence, the specific surface area of 0.5 HDBA is higher compared to that of VER and all other organo-vermiculite combinations.

\subsubsection{DTA/TG}

The results of the thermal analysis of VER, 0.5 and 2.0 HDTMA, and 0.5 and 2.0 HDBA are presented in Figure 6. On DTA, the VER's curve revealed several endothermic effects at the temperatures of $\sim 100{ }^{\circ} \mathrm{C}$ and $200{ }^{\circ} \mathrm{C}$ and also at a higher temperature range of $600-900{ }^{\circ} \mathrm{C}$. For VER, the peak at $\sim 100{ }^{\circ} \mathrm{C}$ corresponds to the removal of water molecules physically absorbed on the expanded vermiculite surface and partially from the vermiculite's interlayer space (Figure 6a). The endothermic peaks at $200{ }^{\circ} \mathrm{C}$ correspond to the second step of removal of water molecules which are intermediately connected with magnesium ions in the vermiculite's interlayer space. At the temperature range of $600-900{ }^{\circ} \mathrm{C}$, an endothermic effect associated with dehydroxylation of vermiculite and the formation of a crystalline structure are observed [50]. The exothermic peak at $\sim 950{ }^{\circ} \mathrm{C}$ corresponds to the formation of a new phase of enstatite [51]. The analysis of TG and quadrupole mass spectra (QMS) shows a 12\% loss of $\mathrm{H}_{2} \mathrm{O}$ molecules, which might be due to the hydration process that takes place at the temperatures of $\sim 100{ }^{\circ} \mathrm{C}$ and $200^{\circ} \mathrm{C}$. Additionally, the hydroxylation of vermiculite (at the temperature range of $600-900{ }^{\circ} \mathrm{C}$ ) is associated with an $8 \%$ loss of $\mathrm{H}_{2} \mathrm{O}$ molecules.

The analysis of DTA curve of HDTMA indicate the occurrence of an endothermic effect $\left(103{ }^{\circ} \mathrm{C}\right.$ and $250^{\circ} \mathrm{C}$ ) which is associated with rearrangements within the alkyl chains of surfactant (Figure 6b). The exothermic peak at $340{ }^{\circ} \mathrm{C}$ is related to the oxidation of HDTMA. The analysis of the TG curve of HDTMA shows a great loss of mass, which is related to oxidation of the surfactant. With the mass decrease, there was a significant increase in $\mathrm{H}_{2} \mathrm{O}$ and $\mathrm{CO}_{2}$ content.

Analysis of the TG curve of HDBA shows a great loss of mass which is related to HDBA decay and the oxidation of degradation products. At a low-temperature range $\left(53^{\circ} \mathrm{C}\right)$, an endothermic effect caused by rearrangements within the surfactant structure was observed on the DTA curve (Figure 6c). In the $250-350{ }^{\circ} \mathrm{C}$ temperature range, there are two exothermic peaks, resulting from the breakdown of the surfactant and formation of $\mathrm{H}_{2} \mathrm{O}$ and $\mathrm{CO}_{2}$.

Analysis of the DTA curves of 0.5 HDTMA and 2.0 HDTMA indicate the occurrence of several endothermic and exothermic effects. At a low-temperature range $\left(30-100^{\circ} \mathrm{C}\right)$, endothermic effects associated with initial dehydration of the vermiculite and rearrangements within the alkyl chains of the surfactant are observed (at $64{ }^{\circ} \mathrm{C}$ and $103{ }^{\circ} \mathrm{C}$, respectively) (Figure 6d,e) [52]. At temperatures above $200{ }^{\circ} \mathrm{C}$, the surfactant oxidizes, which is manifested by the occurrence of exothermic peaks (temperature range: $300-340^{\circ} \mathrm{C}$ ). At temperatures above $700{ }^{\circ} \mathrm{C}$, effects resulting from dehydroxylation and breakdown of the mineral structure are predominantly observed [53,54]. An increase in the amount of surfactant does not lead to major changes in the structure, and changes were observed only for the peak associated with HDTMA pyrolysis. The peak became more sharper, which may be related to different spatial ordering of the surfactant (formation of micelles) [18]. 

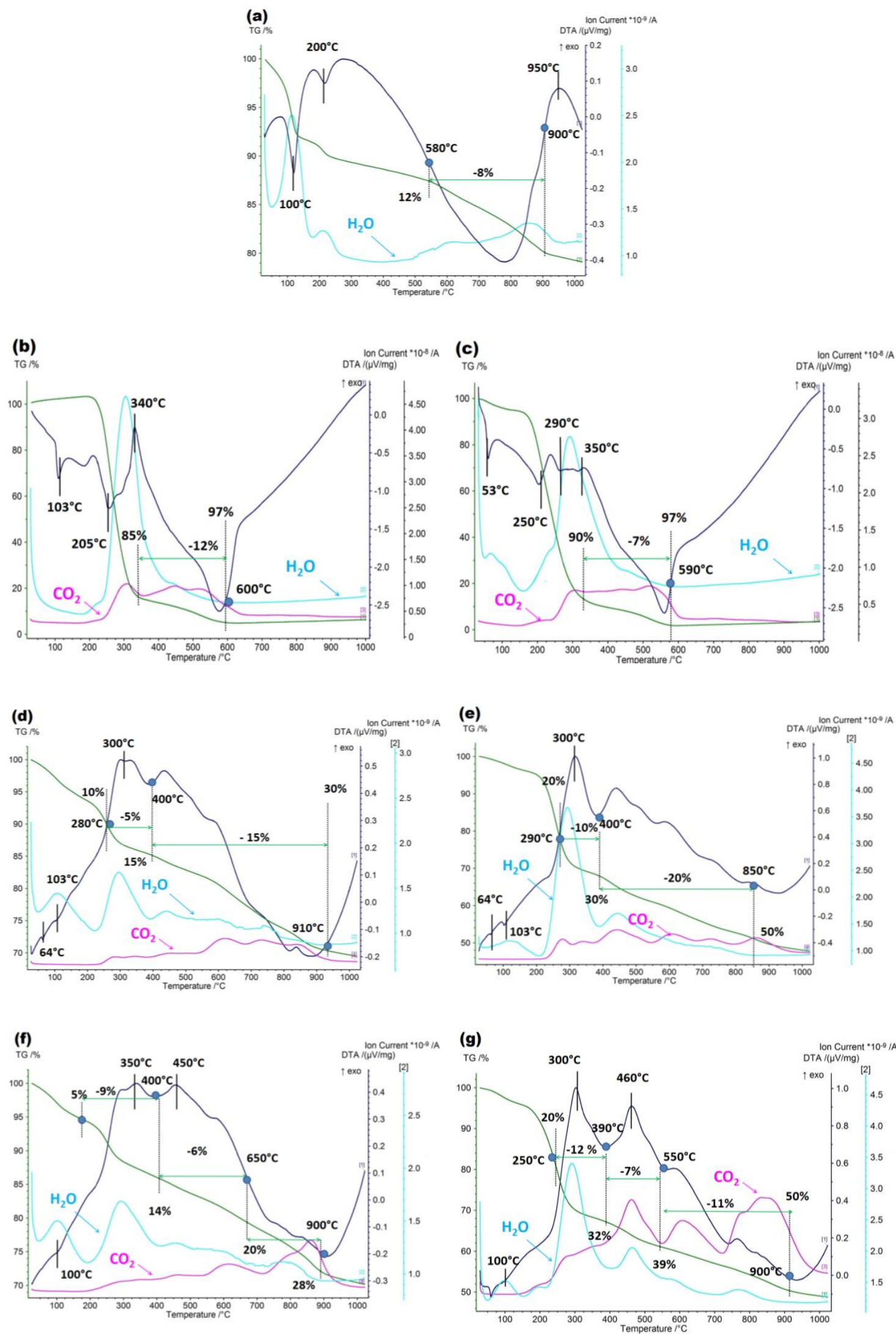

Figure 6. Thermal analysis (DTA/TG) coupled with the measurement of evolved gases composition for: (a) VER, (b) HDTMA, (c) HDBA, (d) 0.5 HDTMA, (e) 2.0 HDTMA, (f) 0.5 HDBA, and (g) 2.0 HDBA. 
Analysis of the TG curves of 0.5 HDTMA and 2.0 HDTMA discloses a lower mass-loss rate, which seems to be associated with the dehydration process, than in the case of VER. This effect is a result of the hydrophobic properties gained by the organo-vermiculite complex, due to a reduction in the amount of water located in the mineral's structure. A greater loss of mass was related to the oxidation of the organic portion of the sample, i.e., the adsorbed surfactant. Moreover, greater the amount of surfactant that was oxidized, greater was the decrease of mass [55]. The loss was accompanied by an increase in $\mathrm{H}_{2} \mathrm{O}$ and $\mathrm{CO}_{2}$ content. With the increase in temperature, an increase in $\mathrm{CO}_{2}$ evolution was observed, with a simultaneous decrease in the amount of water vapor.

The results of the thermal analysis of 0.5 HDBA and 2.0 HDBA are more complex (Figure 6f,g). At a low-temperature range $\left(25-105^{\circ} \mathrm{C}\right)$, an endothermic effect caused by mineral dehydration and rearrangements within the surfactant structure was observed on the DTA curve. In the $300-500{ }^{\circ} \mathrm{C}$ temperature range, two distinct exothermic peaks separated by an endothermic peak were noted, resulting from the breakdown of the surfactant and formation of $\mathrm{H}_{2} \mathrm{O}$ and $\mathrm{CO}_{2}$. The occurrence of these peaks above $300{ }^{\circ} \mathrm{C}$ can indirectly prove the effectiveness of the modification process. The interaction of organic cations with the structure of the mineral minimizes the disintegration of the surfactant and occurs at a temperature higher than that required to disintegrate pure HDBA, what has also been observed in case of other surfacants for example stearyl dimethyl benzyl ammonium chloride (SDBA-Cl) $[49,56]$. At a higher temperature range $\left(>650^{\circ} \mathrm{C}\right)$, an endothermic effect associated with dehydroxylation of the mineral was noted $[52,53]$.

The analysis of the TG curve shows that the largest loss of mass was recorded in the case of HDBA decay and the oxidation of the products of this decay, and the more the concentration of the surfactant, the greater was the mass loss. Significant losses were also observed following dehydration and dehydroxylation processes of vermiculite [53]. These changes were accompanied by the discharge of $\mathrm{CO}_{2}$ and $\mathrm{H}_{2} \mathrm{O}$ molecules. The shape of the QMS curves suggests that HDBA combustion is a long-term process, but it is more homogeneous than burning HDTMA. The final stage of HDBA oxidation process was accompanied by rapid oxidation of $\mathrm{CO}_{2}$ which was observed at $600^{\circ} \mathrm{C}$ and $850{ }^{\circ} \mathrm{C}$.

\subsubsection{SEM}

Figure 7 shows the shape of grain aggregates formed by VER, 0.5 and 2.0 HDTMA, and 0.5 and 2.0 HDBA. The aggregates of VER form specific irregular accordion-shaped grains, consisting of flakes. Since the VER's layers are weakly compacted, a distinct porous microstructure is observed for its grain aggregates (Figure 7a,b). It should be noted that the studies were carried out using expanded VER, which was produced by high-temperature treatment. Under these conditions, molecules of water located in the vermiculite's interlayer space are removed and connections between the layers become weak. Hence, the expanded vermiculite exhibits a highly porous microstructure [57]. The size of grain aggregates falls in the range of $0.5-1 \mathrm{~mm}$. Generally, organo-vermiculite particles show an irregular structure with fine flakes [54,58]. The samples of 0.5 and 2.0 HDTMA form aggregates of similar shape and have a smaller size compared to VER (Figure 7c). It was noted that the greater the amount of surfactant used in the modification process, the greater was the degree of grain compression (Figure 7d). The dependence may be the effect of the modification process, which involves dispersion in water, heating, and drying of the material.

In the case of $0.5 \mathrm{HDBAC}$, the aggregates were characterized by a higher degree of compression than was observed prior to the modification of the mineral, reaching sizes up to $0.5 \mathrm{~mm}$ (Figure 7e). The greater amount of surfactant used in the modification process resulted in partial distortion of the grains and aggregates which became smaller and more compact (Figure 7f). 

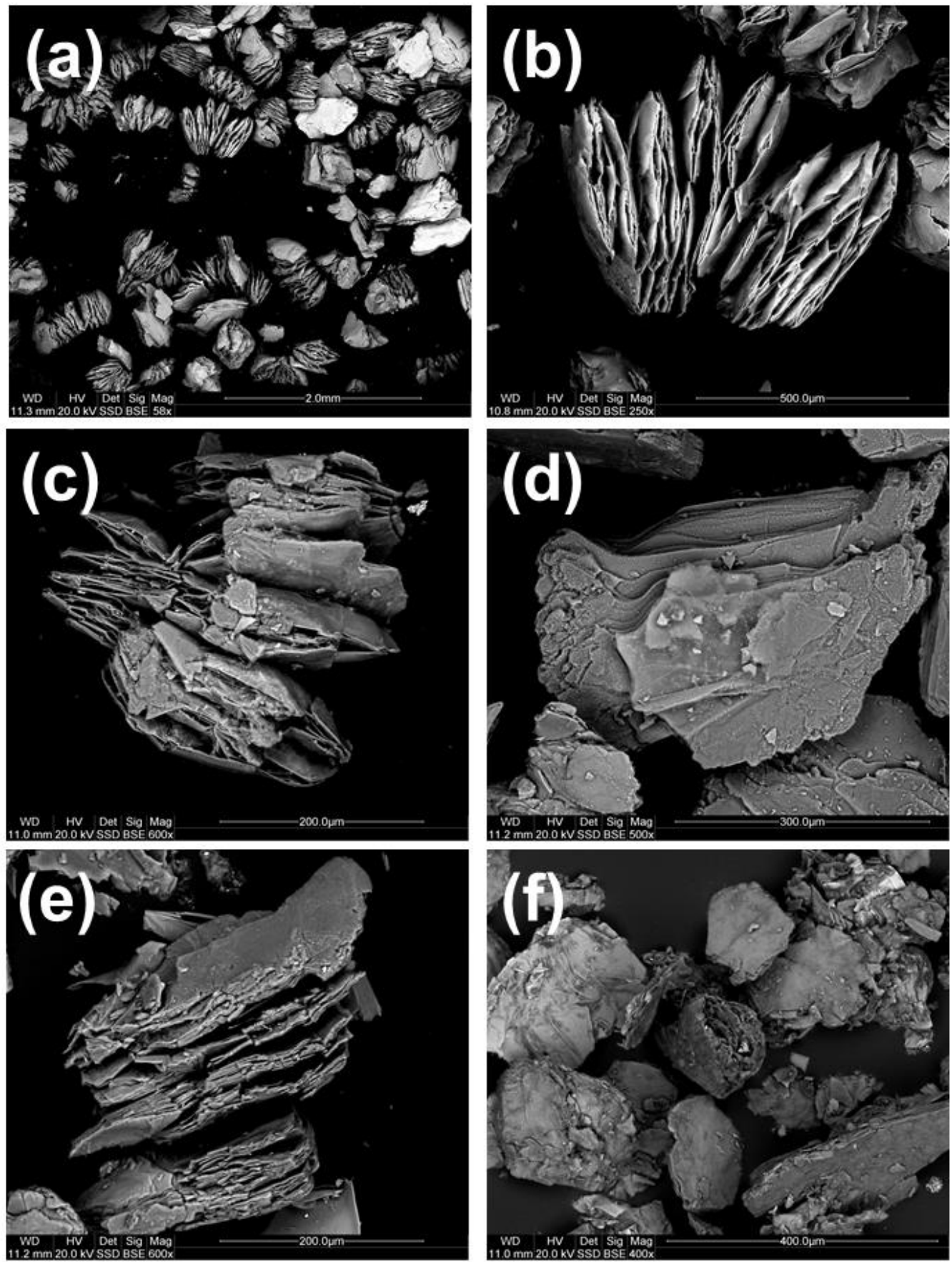

Figure 7. SEM images of: (a) VER, (b) VER, (c) 0.5 HDTMA, (d) 2.0 HDTMA, (e) 0.5 HDBA, and (f) 2.0 HDBA.

\section{Sorption of As(III) and As(V) onto Modified and Unmodified Vermiculite}

\section{1. $p H$ Effect}

The effect of $\mathrm{pH}$ on the sorption of $\mathrm{As}(\mathrm{III})$ and $\mathrm{As}(\mathrm{V})$ is shown in Figure 8. The results revealed that $\mathrm{pH}$ generally does not significantly affect the sorption of $\mathrm{As}(\mathrm{III})$ and $\mathrm{As}(\mathrm{V})$ ions. However, a different trend can be observed in regard to the adsorption of $\mathrm{As}(\mathrm{V})$ on the 2.0 HDTMA—the removal was significantly smaller at $\mathrm{pH}>6$, and regarding the adsorption of As(III) onto 2.0 HDBA, it was observed that sorption does not occur at $\mathrm{pH}>2$. Modification of vermiculite with HDTMA and HDBA does not significantly increase the sorption properties of organo-vermiculites with respect to 
As(III) ion compared to the VER, regardless of the $\mathrm{pH}$ changes. However, the sorption of As(V) is slightly enhanced by the presence of HDTMA and HDBA on the surface of vermiculite, especially for 2.0 HDTMA. The removal of $\mathrm{As}(\mathrm{V})$ at a $\mathrm{pH}<6$ is more than two times greater than that observed for other modifications. The results indicate that the effect caused by $\mathrm{pH}$ changes does not depend on the type of surfactant used for modification. At low initial $\mathrm{pH}$, the equilibrium $\mathrm{pH}$ values for all the samples are similar; if the initial $\mathrm{pH}>6$, differences between the equilibrium $\mathrm{pH}$ values are slightly higher (Figure S1 in Supplementary Materials). Generally, it was observed that the higher the sorption of $\mathrm{As}(\mathrm{III})$ or $\mathrm{As}(\mathrm{V})$ ions, the lower the equilibrium $\mathrm{pH}$ values.

(a)

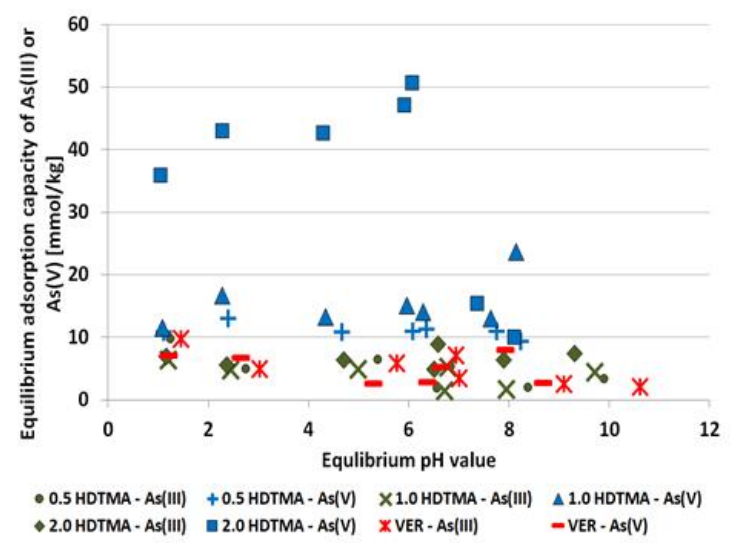

(b)

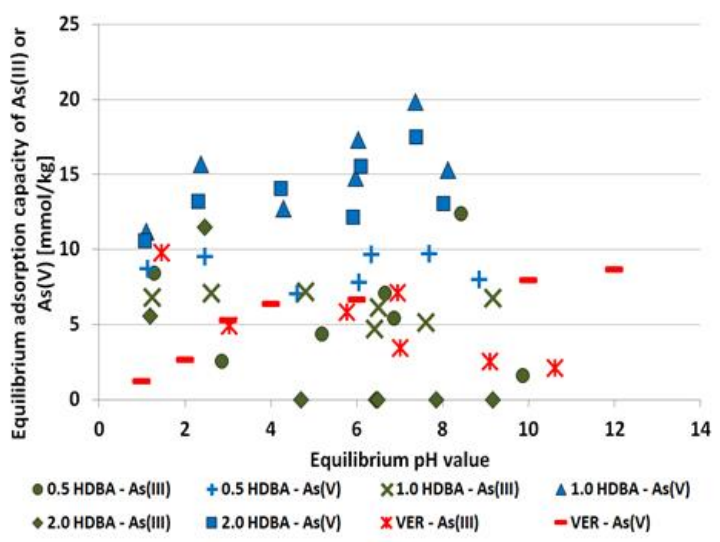

Figure 8. Sorption of $\mathrm{As}(\mathrm{III})$ or $\mathrm{As}(\mathrm{V})$ ions as a function of equilibrium $\mathrm{pH}$ value for (a) VER, 0.5 HDTMA, 1.0 HDTMA, and 2.0 HDTMA, and (b) VER, 0.5 HDBA, 1.0 HDBA, and 2.0 HDBA.

\subsubsection{Initial Concentration Effect}

The results of the experiment performed to determine the effect of concentration on the sorption of $\mathrm{As}(\mathrm{III})$ and $\mathrm{As}(\mathrm{V})$ ions clearly show that an increase in the concentration of sorbate in the solution is associated with an increase in the sorption capacity (Figure 9). This correlation is observed for all sorbents; however, this condition is most obvious for 2.0 HDTMA and 2.0 HDBA modifications. An exception was observed with regard to the sorption of $\mathrm{As}(\mathrm{V})$ at an initial concentration of $10 \mathrm{mmol} / \mathrm{L}$, where the sorption was the same or lower than observed at the initial concentration of $5 \mathrm{mmol} / \mathrm{L}$. The highest efficiency for removal of $\mathrm{As}(\mathrm{III})$ and $\mathrm{As}(\mathrm{V})$ ions from the solution was noticed for 2.0 HDTMA modification, at an initial concentration of $20 \mathrm{mmol} / \mathrm{L}$ and was found to be $209 \mathrm{mmol} / \mathrm{kg}$ and $240.5 \mathrm{mmol} / \mathrm{kg}$, respectively. With an increasing amount of the adsorbed surfactant, the degree of sorption was found to be higher. However, the removal efficiency of $\mathrm{As}(\mathrm{V})$ by 0.5 and 1.0 HDTMA and 0.5 and 1.0 HDBA complexes were relatively low. The sorption capacity of these materials only slightly increased in relation to the sorption capacity of unmodified vermiculite.

The $\mathrm{pH}$ values of all the tested samples considerably increased following the sorption process compared to the $\mathrm{pH}$ values of the basal solutions (Figure S2 in Supplementary Materials). In the case of As(III) sorption, at the low-concentration range, the $\mathrm{pH}$ value after the sorption process increased with an increase in the concentration, whereas at the higher concentration range the $\mathrm{pH}$ value decreased, still maintaining the value higher than the $\mathrm{pH}$ of the basal solution. In the case of $\mathrm{As}(\mathrm{V})$ sorption, the highest $\mathrm{pH}$ value was noted for samples with an initial surfactant concentration of $0.5 \mathrm{CEC}$. As the concentration increased, the $\mathrm{pH}$ value decreased, approaching the value observed before the sorption process.

\subsubsection{Sorbent Dosage Effect}

The results of the experiment performed to determine the effect of sorbent dosage on the sorption of arsenic oxyanions are shown in Figure 10. The amount of arsenic oxyanions removed was enhanced 
by $8 \%$ and $10 \%$ for $\mathrm{As}(\mathrm{III})$ and $\mathrm{As}(\mathrm{V})$ ions, respectively, with increasing dosage of VER. An increasing amount of 0.5 HDBA slightly improved the sorption capacity of arsenic anions. More than $10 \%$ of $\mathrm{As}(\mathrm{III})$ and $\mathrm{As}(\mathrm{V})$ ions are removed at $150 \mathrm{~g} / \mathrm{L}$ concentration of modified sorbents. Surprising results were obtained for 0.5, 2.0 HDTMA and 2.0 HDBA samples. At 10 and $20 \mathrm{~g} / \mathrm{L}$ concentrations of organo-vermiculite, a significant increase in the removal of both arsenic oxyanions was observed. However, further increase in the dosage of 0.5, 2.0 HDTMA and 2.0 HDBA resulted in a decrease of $\mathrm{As}(\mathrm{III})$ and $\mathrm{As}(\mathrm{V})$ sorption to an amount below or comparable to the sorption exhibited by VER.

(a)

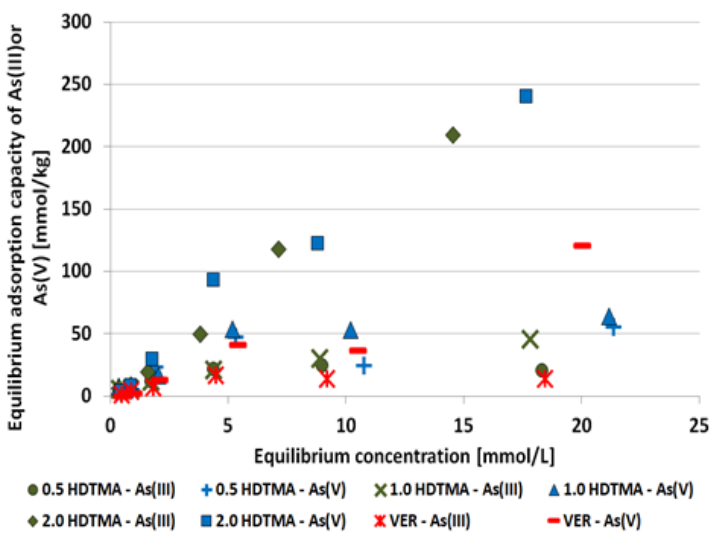

(b)

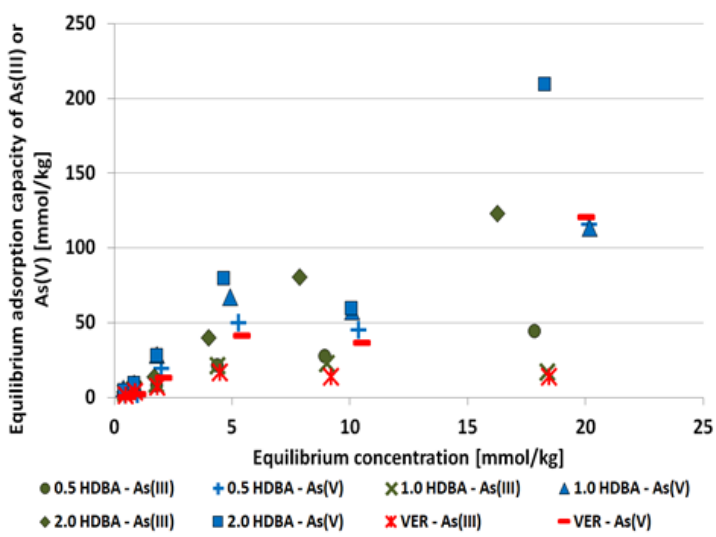

Figure 9. Sorption of $\mathrm{As}(\mathrm{III})$ or $\mathrm{As}(\mathrm{V})$ ions as a function of equilibrium concentration for (a) VER, 0.5 HDTMA, 1.0 HDTMA, and 2.0 HDTMA, and (b) VER, 0.5 HDBA, 1.0 HDBA, and 2.0 HDBA.

(a)

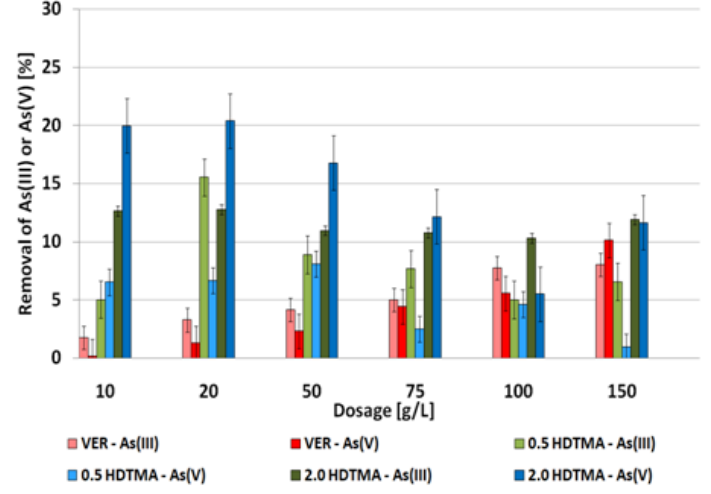

(b)

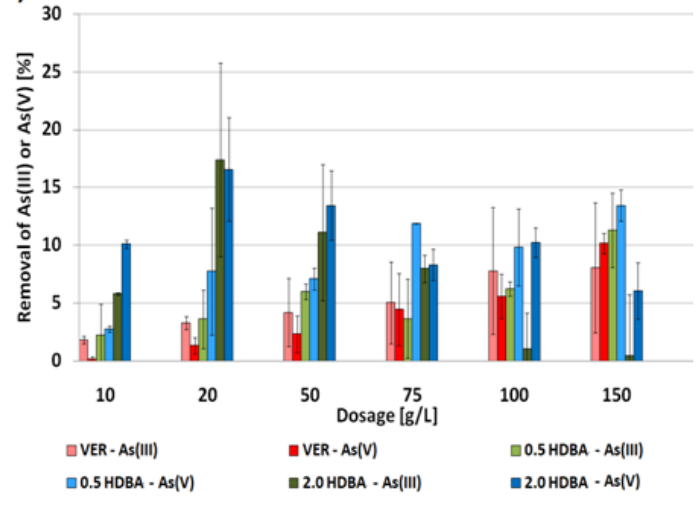

Figure 10. Sorption of $\mathrm{As}(\mathrm{III})$ or $\mathrm{As}(\mathrm{V})$ ions as a function of dosage sorbent for (a) VER, 0.5 HDTMA, and 2.0 HDTMA, and (b) VER, 0.5 HDBA, and 2.0 HDBA.

The results of measured equilibrium $\mathrm{pH}_{\mathrm{eq}}$ values revealed that increased dosage of sorbent resulted in a rise in the $\mathrm{pH}_{\mathrm{eq}}$ values (Figure S3 in Supplementary Materials). However, a higher $\mathrm{pH}$ value was obtained following sorption of $\mathrm{As}(\mathrm{III})$ than for $\mathrm{As}(\mathrm{V})$. In the case of As(V) sorption onto 2.0 HDTMA and 2.0 HDBA, particularly at the dosage range of $10-50 \mathrm{~g} / \mathrm{L}$, the $\mathrm{pH}_{\mathrm{eq}}$ was lower than the $\mathrm{pH}$ value of the basal solution.

\subsubsection{Adsorption Isotherms}

The isotherm representing the sorption of As(III) anions onto VER follows the Langmuir model (Figure 11a; Figure S4a in Supplementary Materials) and shows a high coefficient of correlation, $\mathrm{R}^{2}>0.95$ (Table S1 in Supplementary Materials). The parameters included in the Langmuir isotherm model helped in the determination of maximum sorption capacity, which equals $13.04 \mathrm{mmol} / \mathrm{kg}$. On the other hand, As(V) sorption onto VER is well-described by the Freundlich model (Figure 11b; 
Figure S4b). Similarly, sorption of both arsenic oxyanions onto 0.5 and 2.0 HDTMA and also As(III) onto 1.0 HDTMA fits better to the Freundlich model (Figure 11c; Figure S4c,d,g,k,l). The coefficient of correlation, $\mathrm{R}^{2}$, for $\mathrm{As}(\mathrm{V})$ sorption onto 1.0 HDTMA is slightly higher for the Langmuir model. However, the difference in the $\mathrm{R}^{2}$ coefficients (about 0.02) between Freundlich and Langmuir models was found to be negligible (Table S1). Furthermore, a better fitted experimental data for As(V) sorption was obtained for the Freundlich modeling curve (Figure S4h). Additionally, comparing the adsorption results of $\mathrm{As}(\mathrm{III})$ and $\mathrm{As}(\mathrm{V})$ at concentrations of 0.5 and 2.0 HDTMA suggests that despite an increase in the uptake of HDTMA molecules by the vermiculite, the obtained equilibrium sorption isotherm is still better presented by Freundlich isotherm. Following this deduction, results for As(V) uptake by 1.0 HDTMA are reflected by Freundlich model. Subsequently, As(III) and As(V) adsorption onto 0.5, 1.0, and 2.0 HDBA samples is better described by the Freundlich rather than the Langmuir isotherm model (Figure 11d; Figure S4e,f,i,j,m,n). Taken together, As(III) and As(V) adsorption isotherms for HDTMA- and HDBA-vermiculite combinations fitted better to Freundlich model. The steepness of the isotherm curves is a measure for the selectivity of an adsorption process; the steeper the isotherm, the stronger is the affinity of $\mathrm{As}(\mathrm{III}, \mathrm{V})$ to sorption sites. The flattening of the sorption isotherms indicates the approach of the sorption maxima [24,59-61]. The flattening is more visible for adsorption of $\mathrm{As}(\mathrm{III})$ than for $\mathrm{As}(\mathrm{V})$, especially for vermiculite modified with HDBA. Moreover, for 2.0 HDTMA and 2.0 HDBA flattening cannot be detected for both As(III) and As(V), which means that sorbents have not been saturated.

(a)

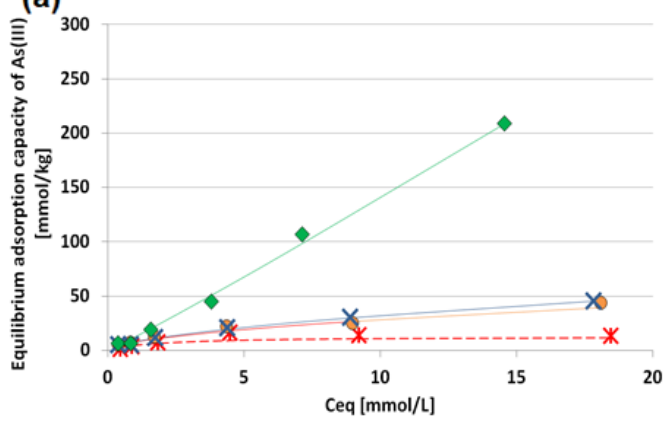

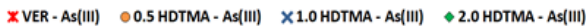
(c)

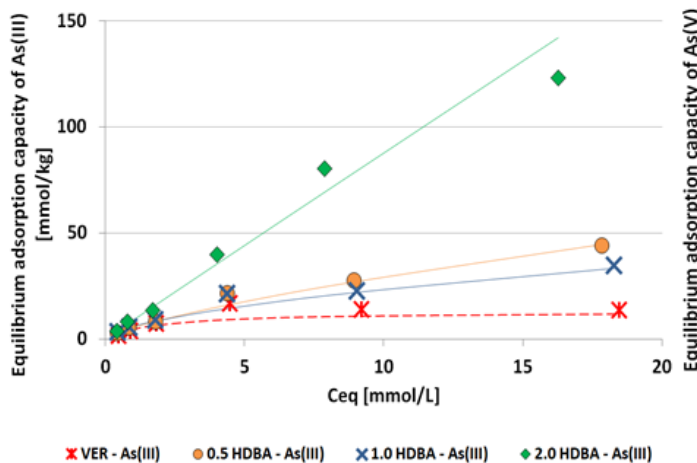

(b)

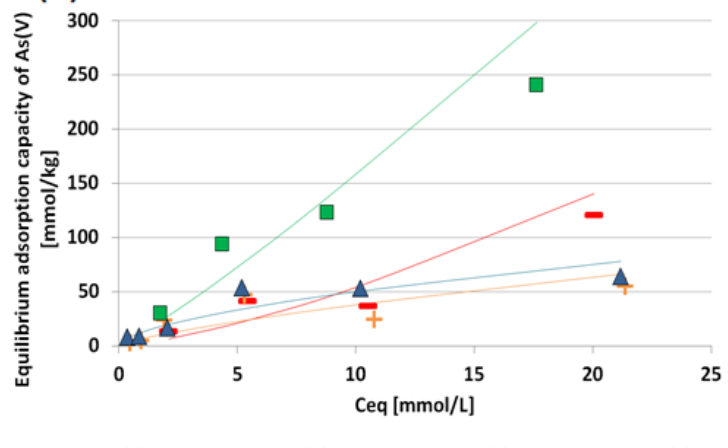

(d)

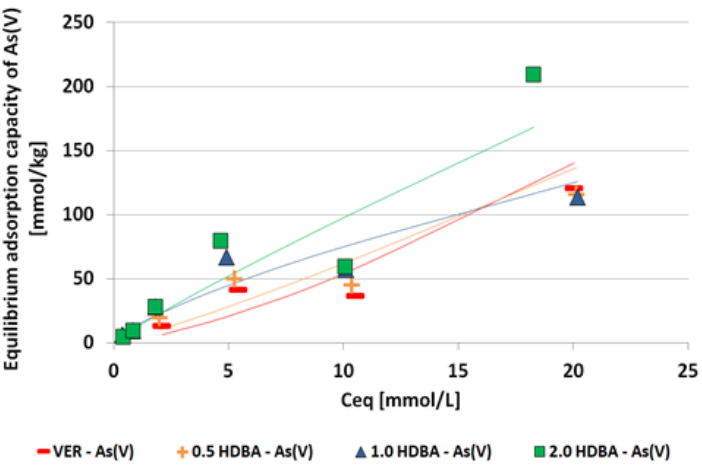

Figure 11. Sorption isotherms of: VER, 0.5 HDTMA, and 2.0 HDTMA for As(III) (a) and for As(V) (b); VER, 0.5 HDBA, and 2.0 HDBA for As(III) (c) and for As(V) (d). The curves that best fit the Langmuir (dotted line) and Freundlich (solid line) models are presented.

\section{Discussion}

Modification of expanded vermiculite involves organic intercalation processes, which occur mainly through an ion exchange reaction between exchangeable cations from the structure of vermiculite and the quaternary ammonium salts with long alkyl chains. In the modified vermiculites, the interlayer 
spacing changes, due to the penetration of organic cations into the interlayer space and the resulting bulk effect. Various studies indicate that if the amount of the added quaternary ammonium salt is small (below CEC of the used mineral), the intercalation occurs mainly via ion exchange; however, when the amount of the added salt exceeds CEC, molecular adsorption also takes place [62,63]. The organic cations that enter into the vermiculite's interlayer space are arranged into different orientations and cause a change in the thickness of crystal layers of the mineral.

Various studies relating to the modification of vermiculite indicate the formation of a paraffin-type arrangement in the interlayer space of the vermiculite. The type of arrangement depends on the organic cation size and the surface charge of the mineral. Small organic cations form monolayers in smectites; however, they must form bilayers in vermiculites to neutralize the greater charge. The attractive forces between the interlayer organic cations and the highly charged silicate surfaces are greater in vermiculites than in smectites. Therefore, for larger organic cations (like HDTMA and HDBA used in this study), bilayers are formed in smectites whereas paraffin complexes are formed in vermiculites $[24,26,36,63-67]$. The XRD results obtained in this study are similar to that reported in the literature data, which allows us to assume that during the modification of vermiculite, the paraffin-type arrangement occurs in the interlayer space of organo-vermiculites [24,31,68,69].

The reflections shown by the 2.0 HDTMA and 2.0 HDBA complexes appear to be sharper and better defined than those shown for the modification with $0.5 \mathrm{CEC}$. Well-defined, narrow reflections correspond not only to the larger amount of surfactant on the vermiculite's surface, but also to the well-ordered crystal structure [24,26]. The differences observed with regard to the shape and position of the reflections, which depend on the type of modification, are in agreement with published studies about the influence of ammonium salt concentration on the intercalation process [30,36,70-72].

The surface area and porosity of organo-vermiculites were significantly reduced. These findings are consistent with various literature data [66,73]. The effect of these changes is also visible in the SEM images. The organo-vermiculite aggregates are characterized by a higher degree of compression than before the modification-aggregates became smaller and more compact. Furthermore, with the continuous addition of the surfactant, the lamellar structure of vermiculite disappears [74,75]. The occurrence of the DTA/TG and IR bands, which are characteristic for HDTMA and HDBA, alongside with the results of the analyses discussed above suggest that the modification of vermiculite with HDTMA and HDBA was successful. However, it should be noted that according to some previous studies, vermiculites treated with organic cations usually still contain unmodified layers [4,32]. This condition is mostly due to the formation of a hydrophobic barrier at the edges of large-sized crystals, which makes it difficult for the hydrated inorganic cations to diffuse out of the interlayer space [42,43]. Thus, some interlayer spaces may not be completely filled with organic cations, or interlayer spaces with exchangeable inorganic cations may remain. Nevertheless, even if the modification was not complete, both organo-vermiculites exhibit hydrophobic properties, which are characteristic to modified clays.

Clay minerals have been recognized as good sorbents of cations; however, they can also retain anions and neutral species. The immobilization of anions takes place on sites of temporary positive charge, like $\mathrm{AlOH}_{2}{ }^{+}$and (in case of substitution of $\mathrm{Fe}^{3+}$ for $\mathrm{Al}^{3+}$ ) $\mathrm{FeOH}_{2}{ }^{+}$, formed by association of $\mathrm{H}^{+}$ ions with amphoteric $\mathrm{OH}$ and $\mathrm{O}$ on the clay mineral surfaces [76,77]. However, despite the fact that clay minerals are capable of uptaking anions, experiments concerning the removal of arsenic ions with VER revealed that its sorption capacity toward anions is poor, which was also proven before by other studies $[24,77,78]$.

The previous studies disclosed that for different organo-clay minerals, anions selectivity depend mostly on the type of organic cation applied and also on the type of clay mineral [24]. Moreover, uptake of anions by organo-vermiculites might be hindered-the diffusion of anions is limited due to structures in their interlayer space, which are most probably the paraffin-type arrangements in vermiculites [24]. In addition, for the coarse vermiculite platelets, diffusion pathways for anions from edge sites of the platelets to adsorption sites in the middle are long, and the adsorption of anions at sites in the interlayer space also depends on the equivalent desorption of original anions, which have 
to diffuse through the interlayer space, which can explain the poor sorption capacity of vermiculites in comparison to other clay minerals [24].

The differences between the sorption capacities of organo-vermiculites under different $\mathrm{pH}$ conditions could be related to the speciation of arsenic. The dominant speciations for As(V) are $\mathrm{HAsO}_{4}{ }^{2-}$ or $\mathrm{H}_{2} \mathrm{AsO}_{4}{ }^{-}$and $\mathrm{H}_{3} \mathrm{AsO}_{3}{ }^{0}$ for As(III); thus, changing of the surface charge does not have a significant impact on the behavior of zero-valent species of As(III), but on the other hand, increasing $\mathrm{pH}$ may cause competition between anionic forms of $\mathrm{As}(\mathrm{V})$ and $\mathrm{OH}^{-}$groups [79-81]. This explains poor sorption capacity of vermiculites regarding As(III)—zero-valent species of As(III) is reluctantly immobilized by vermiculites and organo-vermiculites. It should also be noted that at $\mathrm{pH}$ value $<6, \mathrm{As}$ predominantly exists as a single-negative form $\left(\mathrm{H}_{2} \mathrm{AsO}_{4}{ }^{-}\right)$, while at a higher $\mathrm{pH}$ value double-negative forms $\left(\mathrm{HAsO}_{4}{ }^{2-}\right)$ predominate. In the case of a one-negative form, one active center is sufficient for sorption to occur, whereas in the case of a two-negative form, two such centers are necessary [22,82]. Therefore, the effectiveness of $\mathrm{As}(\mathrm{V})$ sorption strongly depends on the $\mathrm{pH}$ of the solution.

In addition, adsorption of oxy-anionic species onto clay and organo-clay minerals is favorable when the $\mathrm{pH}$ is low, and maximum adsorption is usually achieved at $\mathrm{pH} 3-5$ [24,83-85], which may suggest that the interaction occurred mainly due to the formation of inner-sphere complexes through silanol and aluminol groups present at the edges of clay mineral particles [78,85]. The observed dependency could also be due to the protonation/deprotonation reactions of the functional groups present on the surface of the organo-clays. Protonation at low $\mathrm{pH}$ usually increases the anion exchange capacity of the mineral [24]. Dultz et al. [24] suggest that the uptake of molecules (cation-anion pairs) and the protonation of functional groups are the most important mechanisms that prompt the immobilization of anions on the organo-clays. Initial concentration is also known to affect the effectiveness of As(III) and As(V) sorption. This may be associated with the surface coverage by ions and the active centers occupied by them. It is assumed that active centers are occupied first with ions that permanently get attached to the surface and no further changes occur. If more ions are available, then more sites are occupied [86].

The results obtained in the experiment to determine the sorption efficiency of As(III) and As(V) as a function of dosage indicate that against expectations, the higher dosage of sorbent does not increase the amount of the absorbed arsenic. An important factor that can potentially inhibit sorption is the high swelling capacity of vermiculite in contact with water. In cases where samples are treated with high sorbent doses, creating optimal conditions for sorption becomes difficult. Hence, at high doses, the interface between sorbate and sorbent becomes limited. The boundary layers are usually characterized by highest activity and hence the separation surface should be increased as much as possible, which in turn can be achieved by appropriate dispersion of the solid phase in the sorbate solution [87]. Increasing the density of the vermiculite suspension, with its significant swelling, caused a disturbance of the proportion between the solid and the solution, making some of the active sites of the mineral to be unavailable to sorbate. $\mathrm{pH}$ measurements revealed that at higher dosages, the $\mathrm{pH}$ value of the solution was also high. The $\mathrm{pH}$ increase results from the fact that vermiculite strongly alkalizes the solution-the $\mathrm{pH}$ of the aqueous suspension of this mineral is alkaline in nature and is usually in the range of 8-9 [88].

\section{Conclusions}

The modification process of expanded vermiculite with used HDTMA-Br and HDBA-Cl was successful. The present study shows distinct alteration in the properties of modified vermiculite, including changes its grain morphology, partial hydrophobization of surface, deterioration textural parameters (an exception is 0.5 HDBA, where higher porosity is observed) and increase interlayer space due to the fact that organic modification is controlled mainly by intercalation process and takes place only the on external and internal surface of vermiculite. The obtained results revealed that the modification process of vermiculite with different concentrations of HDTMA and HDBA and further utilization of the prepared organo-vermiculites for immobilization of arsenic compounds are more 
complex than suspected. The effectiveness of arsenic oxyanions sorption onto organo-vermiculite slightly depended on the $\mathrm{pH}$ of the arsenic solution. However, the higher alkalization of solution $(\mathrm{pH}$ $>6$ ), impacts on the decreased sorption of As(III) and As(V). Under these conditions, low sorption of arsenic oxyanions is caused mainly by the presence of the competition effect between zerovalent As(III) and bivalent $\mathrm{As}(\mathrm{V})$ species and $\mathrm{OH}^{-}$groups. Nevertheless, a better sorption capacity was received for $\mathrm{As}(\mathrm{V})$ than for As(III). On the other hand, the results suggest that As (III, V) sorption capacity is greater with an increasing amount of HDTMA and HDBA adsorbed onto vermiculite. The maximum sorption capacity equaling $209 \mathrm{mmol} / \mathrm{kg}$ for As(III) and $240.5 \mathrm{mmol} / \mathrm{kg}$ for As(V) was obtained by used 2.0 HDTMA at the initial concentration of $20 \mathrm{mmol} / \mathrm{As}(\mathrm{III}, \mathrm{V}) \mathrm{L}$. Moreover, the optimal sorption conditions, which were achieved at the low dosage of organo-vermiculite at the range 10-20 g/L, may be associated with obtaining a favorable proportion between the amount of sorbent and sorbate.

The modification of most of the clay minerals with HDTMA is well-described; however; there is still a lack of information regarding the use of HDBA. Our study revealed that HDBA can be used for effective modification of clay minerals, but in future studies, the effect of the surfactant on the interlayer structure has to be determined in more detail, including the characteristics of the spaces at the adsorption sites and the diffusion mechanisms for penetration of anions into the interlayer space.

Supplementary Materials: The following are available online at http:/www.mdpi.com/2075-163X/9/8/483/s1, Figure S1: Changes of $\mathrm{pH}$ value measured in solutions of $\mathrm{As}(\mathrm{III})(\mathrm{a})$ and $\mathrm{As}(\mathrm{V})$ (b) before and after sorption experiment carried out onto diverse initial $\mathrm{pH}$ value of raw and modified vermiculite. Figure S2: Changes of $\mathrm{pH}$ value measured in solutions of $\mathrm{As}(\mathrm{III})(\mathrm{a})$ and $\mathrm{As}(\mathrm{V})(\mathrm{b})$ before and after sorption experiment carried out onto diverse initial concentration of raw and modified vermiculite. Figure S3: Changes of pH value measured in solutions of $\mathrm{As}(\mathrm{III})(\mathrm{a})$ and $\mathrm{As}(\mathrm{V})(\mathrm{b})$ before and after sorption experiment carried out onto diverse dosage of raw and modified vermiculite. Figure S4: Linearization of Freundlich and Langmuir model for sorption of As(III) (a), $\mathrm{As}(\mathrm{V})$ onto raw vermiculite (b); sorption of As(III) (c), As(V) onto 0.5 HDTMA (d) and As (III) (e), As(V) onto 0.5 HDBA (f); As(III) (g), As(V) onto 1.0 HDTMA (h) and As(III) (i), As(V) onto 1.0 HDBA (j); sorption of As(III) (k), As(V) onto 2.0 HDTMA (l) and As(III) (m), As(V) onto 2.0 HDBA (n). Table S1: Freundlich and Langmuir model coefficients for sorption of $\mathrm{As}(\mathrm{III})$ and $\mathrm{As}(\mathrm{V})$ onto raw and modified vermiculite.

Author Contributions: T.B. designed and supervised the project; A.K. performed the experiments; M.T., M.W., A.S. and A.K. analyzed the data; M.T., M.W. and A.S. wrote this paper and T.B. reviewed it.

Funding: This research was funded by AGH-UST, grant number 16.16.140.315.

Conflicts of Interest: The authors declare no conflict of interest. The funders had no role in the design of the study; in the collection, analyses or interpretation of data; in the writing of the manuscript and in the decision to publish the results.

\section{References}

1. Bakshi, S.; Banik, C.; Rathke, S.J.; Laird, D.A. Arsenic sorption on zero-valent iron-biochar complexes. Water Res. 2018, 137, 153-163. [CrossRef] [PubMed]

2. Debure, M.; Tournassat, C.; Lerouge, C.; Made, B.; Robinet, J.C.; Fernandez, A.M.; Grangeon, S. Retention of arsenic, chromium and boron on an outcropping clay-rich rock formation (the Tegulines Clay, eastern France). Sci. Total Environ. 2018, 642, 216-229. [CrossRef] [PubMed]

3. Mandal, B.K.; Suzuki, K.T. Arsenic round the world: A review. Talanta 2002, 58, 201-235. [CrossRef]

4. Vahidnia, A.; Van der Voet, G.B.; de Wolf, F.A. Arsenic neurotoxicity-A review. Hum. Exp. Toxicol. 2007, 26, 823-832. [CrossRef] [PubMed]

5. Sarkar, A.; Paul, B. The global menace of arsenic and its conventional remediation-A critical review. Chemosphere 2016, 158, 37-49. [CrossRef] [PubMed]

6. Sowers, T.D.; Harrington, J.M.; Polizzotto, M.L.; Duckworth, O.W. Sorption of arsenic to biogenic iron (oxyhydr) oxides produced in circumneutral environments. Geochim. Cosmochim. Acta 2017, 198, $194-207$. [CrossRef]

7. The World Health Organization. Guideliness for drinking-water quality. WHO Chron. 2011, 38, 104-108.

8. Elwakeel, K.Z.; Guibal, E. Arsenic(V) sorption using chitosan/ $\mathrm{Cu}(\mathrm{OH})_{2}$ and chitosan/CuO composite sorbents. Carbohydr. Polym. 2015, 134, 190-204. [CrossRef]

9. Ali, I. The Quest for Active Carbon Adsorbent Substitutes: Inexpensive Adsorbents for Toxic Metal Ions Removal from Wastewater. Sep. Purif. Rev. 2010, 39, 95-171. [CrossRef] 
10. Yu, Y.; Zhao, C.W.; Wang, Y.G.; Fan, W.H.; Luan, Z.K. Effects of ion concentration and natural organic matter on $\operatorname{arsenic}(\mathrm{V})$ removal by nanofiltration under different transmembrane pressures. J. Environ. Sci. 2013, 25, 302-307. [CrossRef]

11. Wang, Y.X.; Duan, J.M.; Liu, S.X.; Li, W.; van Leeuwen, J.; Mulcahy, D. Removal of As(III) and As(V) by ferric salts coagulation-Implications of particle size and zeta potential of precipitates. Sep. Purif. Technol. 2014, 135, 64-71. [CrossRef]

12. Wang, S.S.; Gao, B.; Zimmerman, A.R.; Li, Y.C.; Ma, L.; Harris, W.G.; Migliaccio, K.W. Removal of arsenic by magnetic biochar prepared from pinewood and natural hematite. Bioresour. Technol. 2015, 175, 391-395. [CrossRef]

13. Chen, W.F.; Parette, R.; Zou, J.Y.; Cannon, F.S.; Dempsey, B.A. Arsenic removal by iron-modified activated carbon. Water Res. 2007, 41, 1851-1858. [CrossRef]

14. Ocinski, D.; Jacukowicz-Sobala, I.; Mazur, P.; Raczyk, J.; Kociolek-Balawejder, E. Water treatment residuals containing iron and manganese oxides for arsenic removal from water-Characterization of physicochemical properties and adsorption studies. Chem. Eng. J. 2016, 294, 210-221. [CrossRef]

15. Li, Z.H.; Jean, J.S.; Jiang, W.T.; Chang, P.H.; Chen, C.J.; Liao, L.B. Removal of arsenic from water using Fe-exchanged natural zeolite. J. Hazard. Mater. 2011, 187, 318-323. [CrossRef]

16. Yu, W.T.; Luo, M.B.; Yang, Y.X.; Wu, H.; Huang, W.; Zeng, K.; Luo, F. Metal-organic framework (MOF) showing both ultrahigh $\mathrm{As}(\mathrm{V})$ and $\mathrm{As}(\mathrm{III})$ removal from aqueous solution. J. Solid State Chem. 2019, 269, $264-270$. [CrossRef]

17. Tuchowska, M.; Rzepa, G.; Debiec-Andrzejewska, K.; Drewniak, Ł.; Bajda, T. Immobilization of arsenic compounds by bog iron ores. Desalin. Water Treat. 2019, 157, 138-147. [CrossRef]

18. Su, X.L.; Ma, L.Y.; Wei, J.M.; Zhu, R.L. Structure and thermal stability of organo-vermiculite. Appl. Clay Sci. 2016, 132, 261-266. [CrossRef]

19. Li, Z.H.; Bowman, R.S. Retention of inorganic oxyanions by organo-kaolinite. Water Res. 2001, 35, 3771-3776. [CrossRef]

20. Lee, S.Y.; Kim, S.J. Adsorption of naphthalene by HDTMA modified kaolinite and halloysite. Appl. Clay Sci. 2002, 22, 55-63. [CrossRef]

21. Wang, L.; Chen, Z.Y.; Wang, X.; Yan, S.Y.; Wang, J.H.; Fan, Y.W. Preparations of organo-vermiculite with large interlayer space by hot solution and ball milling methods: A comparative study. Appl. Clay Sci. 2011, 51, 151-157. [CrossRef]

22. Bajda, T.; Klapyta, Z. Adsorption of chromate from aqueous solutions by HDTMA-modified clinoptilolite, glauconite and montmorillonite. Appl. Clay Sci. 2013, 86, 169-173. [CrossRef]

23. Riebe, B.; Dultz, S.; Bunnenberg, C. Temperature effects on iodine adsorption on orgrano-clay minerals I. Influence of pretreatment and adsorption temperature. Appl. Clay Sci. 2005, 28, 9-16. [CrossRef]

24. Dultz, S.; An, J.H.; Riebe, B. Organic cation exchanged montmorillonite and vermiculite as adsorbents for $\mathrm{Cr}$ (VI): Effect of layer charge on adsorption properties. Appl. Clay Sci. 2012, 67-68, 125-133. [CrossRef]

25. Liu, S.; Wu, P.X.; Chen, M.Q.; Yu, L.F.; Kang, C.X.; Zhu, N.W.; Dang, Z. Amphoteric modified vermiculites as adsorbents for enhancing removal of organic pollutants: Bisphenol A and Tetrabromobisphenol A. Environ. Pollut. 2017, 228, 277-286. [CrossRef]

26. Placha, D.; Simha Martynkova, G.; Bachmatiuk, A.; Peikertova, P.; Seidlerova, J.; Rummeli, M.H. The influence of $\mathrm{pH}$ on organovermiculite structure stability. Appl. Clay Sci. 2014, 93-94, 17-22. [CrossRef]

27. Martynkova, G.S.; Valaskova, M.; Capkova, P.; Matejka, V. Structural ordering of organovermiculite: Experiments and modeling. J. Colloid Interface Sci. 2007, 313, 281-287. [CrossRef]

28. Reeve, P.J.; Fallowfield, H.J. The toxicity of cationic surfactant HDTMA-Br, desorbed from surfactant modified zeolite, towards faecal indicator and environmental microorganisms. J. Hazard. Mater. 2017, 339, 208-215. [CrossRef]

29. Wolowiec, M.; Muir, B.; Zieba, K.; Bajda, T.; Kowalik, M.; Franus, W. Experimental Study on the Removal of VOCs and PAHs by Zeolites and Surfactant-Modified Zeolites. Energy Fuels 2017, 31, 8803-8812. [CrossRef]

30. Placha, D.; Martynkova, G.S.; Rummeli, M.H. Preparation of organovermiculites using HDTMA: Structure and sorptive properties using naphthalene. J. Colloid Interface Sci. 2008, 327, 341-347. [CrossRef]

31. Kooli, F. Thermal stability investigation of organo-acid-activated clays by TG-MS and in situ XRD techniques. Thermochim. Acta 2009, 486, 71-76. [CrossRef] 
32. Huang, L.; Zhang, X.P.; Wang, Q.Q.; Han, Y.J.; Fang, Y.X.; Dong, S.J. Shape-Control of Pt-Ru Nanocrystals: Tuning Surface Structure for Enhanced Electrocatalytic Methanol Oxidation. J. Am. Chem. Soc. 2018, 140, 1142-1147. [CrossRef]

33. Bergaya, F.; Lagaly, G.; Vayer, M. Cation and anion exchange. In Handbook of Clay Science, 1st ed.; Bergaya, F., Theng, B.K.G., Eds.; Elsevier: Amsterdam, The Netherlands, 2006; Volume 1, pp. 979-1001.

34. Langmuir, I. The constitution and fundamental properties of solids and liquids Part I Solids. J. Am. Chem. Soc. 1916, 38, 2221-2295. [CrossRef]

35. Freundlich, H.M.F. Uber die Adsorption in Losungen. Z. Phys. Chem. 1906, 57, 385-470. [CrossRef]

36. Hundakova, M.; Tokarsky, J.; Valaskova, M.; Slobodian, P.; Pazdziora, E.; Kimmer, D. Structure and antibacterial properties of polyethylene/organo-vermiculite composites. Solid State Sci. 2015, 48, 197-204. [CrossRef]

37. Madejova, J.; Komadel, P. Baseline studies of The Clay Minerals Society Source Clays: Infrared methods. Clays Clay Miner. 2001, 49, 410-432. [CrossRef]

38. Madejova, J. FTIR techniques in clay mineral studies. Vib. Spectrosc. 2003, 31, 1-10. [CrossRef]

39. He, H.; Frost, L.R.; Zhu, J. Infrared study of HDTMA ${ }^{+}$intercalated montmorillonite. Spectrochim. Acta Part A Mol. Biomol. Spectrosc. 2004, 60, 2853-2859.

40. Li, Z.H.; Jiang, W.T.; Hong, H.L. An FTIR investigation of hexadecyltrimethylammonium intercalation into rectorite. Spectrochim. Acta Part A Mol. Biomol. Spectrosc. 2008, 71, 1525-1534. [CrossRef]

41. Shan, Y.; Zeng, P.; Song, Y.; Guo, Y.; Galarneau, A.; Manero, M.-H. Amino-Modified Hydrogen-Bonding Resin and its Adsorption on Berberine. Appl. Mech. Mater. 2013, 448-453, 145-149. [CrossRef]

42. Aroke, U.O.; El-Nafaty, U. XRF, XRD and FTIR Properties and Characterization of HDTMA-Br Surface Modified Organo-Kaolinite Clay. Int. J. Emerg. Technol. Adv. Eng. 2014, 4, 817-825.

43. Madejova, J.; Sekerakova, L.; Bizovska, V.; Slany, M.; Jankovic, L. Near-infrared spectroscopy as an effective tool for monitoring the conformation of alkylammonium surfactants in montmorillonite interlayers. Vib. Spectrosc. 2016, 84, 44-52. [CrossRef]

44. McMurry, J. Organic Chemistry, 7th ed.; Thomson Brooks Cole: Belmont, KY, USA, 2008; Volume 1, p. 1318.

45. Zhang, H.L.; Yu, J.Y.; Wu, S.P. Effect of montmorillonite organic modification on ultraviolet aging properties of SBS modified bitumen. Constr. Build. Mater. 2012, 27, 553-559. [CrossRef]

46. Mozgawa, W.; Krol, M.; Bajda, T. IR spectra in the studies of anion sorption on natural sorbents. J. Mol. Struct. 2011, 993, 109-114. [CrossRef]

47. Wang, J.; Gao, M.; Shen, T.; Yu, M.; Xiang, Y.; Liu, J. Insights into the efficient adsorption of rhodamine B on tunable organo-vermiculites. J. Hazard. Mater. 2019, 15, 501-511. [CrossRef]

48. Sing, K.S.W.; Everett, D.H.; Haul, R.A.W.; Moscou, L.; Pierotti, R.A.; Rouquerol, J.; Siemieniewska, T. Reporting Physisorption Data for Gas Solid Systems with Special Reference to The Determination of Surface-Area and Porosity (Recommendations 1984). Pure Appl. Chem. 1985, 57, 603-619. [CrossRef]

49. Apreutesei, R.E.; Catrinescu, C.; Teodosiu, C. Surfactant-modified natural zeolites for environmental applications in water purification. Environ. Eng. Manag. J. 2008, 7, 149-161.

50. Perez-Maqueda, L.A.; Balek, V.; Poyato, J.; Perez-Rodriquez, J.L.; Subrt, J.; Bountsewa, I.M.; Beckman, I.N.; Malek, Z. Study of natural and ion exchanged vermiculite by emanation thermal analysis, TG, DTA and XRD. J. Therm. Anal. Calorim. 2003, 71,715-726. [CrossRef]

51. Perez-Maqueda, L.A.; Maqueda, C.; Perez-Rodriguez, J.L.; Subrt, J.; Cerny, Z.; Balek, V. Thermal behaviour of ground and unground acid leached vermiculite. J. Therm. Anal. Calorim. 2012, 107, 431-438. [CrossRef]

52. Liu, S.; Wu, P.X.; Yu, L.F.; Li, L.P.; Gong, B.N.; Zhu, N.W.; Dang, Z.; Yang, C. Preparation and characterization of organo-vermiculite based on phosphatidylcholine and adsorption of two typical antibiotics. Appl. Clay Sci. 2017, 137, 160-167. [CrossRef]

53. Liu, Y.; Xiao, D.; Li, H. Kinetics and thermodynamics of lead(II) adsorption on vermiculite. Sep. Sci. Technol. 2007, 42, 185-202. [CrossRef]

54. Yu, M.M.; Gao, M.L.; Shen, T.; Wang, J. Organo-vermiculites modified by low-dosage Gemini surfactants with different spacers for adsorption toward p-nitrophenol. Colloids Surf. A Physicochem. Eng. Asp. 2018, 553, 601-611. [CrossRef]

55. Wu, N.; Wu, L.M.; Liao, L.B.; Lv, G.C. Organic intercalation of structure modified vermiculite. J. Colloid Interface Sci. 2015, 457, 264-271. [CrossRef] 
56. Lemic, J.; Tomasevic-Canovic, M.; Adamovic, M.; Kovacevic, D.; Milicevic, S. Competitive adsorption of polycyclic aromatic hydrocarbons on organo-zeolites. Microporous Mesoporous Mater. 2007, 105, 317-323. [CrossRef]

57. Xu, B.W.; Ma, H.Y.; Lu, Z.Y.; Li, Z.J. Paraffin/expanded vermiculite composite phase change material as aggregate for developing lightweight thermal energy storage cement-based composites. Appl. Energy 2015, 160, 358-367. [CrossRef]

58. Wang, J.; Gao, M.L.; Ding, F.; Shen, T. Organo-vermiculites modified by heating and gemini pyridinium surfactants: Preparation, characterization and sulfamethoxazole adsorption. Colloids Surf. A Physicochem. Eng. Asp. 2018, 546, 143-152. [CrossRef]

59. Kyzioł, J. Minerały Ilaste Jako Sorbenty Metali Ciężkich; Zakład Narodowy im; Ossolińskich; Wydawnictwo Polskiej Akademii Nauk: Wrocław, Poland, 1994; Volume 43, p. 89.

60. El-Bayaa, A.A.; Badawy, N.A.; AlKhalik, E.A. Effect of ionic strength on the adsorption of copper and chromium ions by vermiculite pure clay mineral. J. Hazard. Mater. 2009, 170, 1204-1209. [CrossRef]

61. Shirvani, M.; Kalbasi, M.; Shariatmadari, H.; Nourbakhsh, F.; Najafi, B. Sorption-desorption of cadmium in aqueous palygorskite, sepiolite, and calcite suspensions: Isotherm hysteresis. Chemosphere 2006, 65, 2178-2184. [CrossRef]

62. Czimerova, A.; Bujdak, J.; Dohrmann, R. Traditional and novel methods for estimating the layer charge of smectites. Appl. Clay Sci. 2006, 34, 2-13. [CrossRef]

63. Peng, T.J.; Sun, H.J.; Sun, J.M.; Liu, H.F. Chemical Reaction Characteristics of HDTMA ${ }^{+}$Cations in Inter layer Space of Vermiculite Crystal Layers. Adv. Mater. Res. 2010, 96, 15-20. [CrossRef]

64. Jaynes, W.F.; Boyd, S.A. Clay Mineral Type and Organic-Compound Sorption by Hexadecyltrimethlyammonium-Exchanged Clays. Soil Sci. Soc. Am. J. 1991, 55, 43-48. [CrossRef]

65. Slade, P.G.; Gates, W.P. The swelling of HDTMA smectites as influenced by their preparation and layer charges. Appl. Clay Sci. 2004, 25, 93-101. [CrossRef]

66. Abate, G.; dos Santos, L.B.O.; Colombo, S.M.; Masini, J.C. Removal of fulvic acid from aqueous media by adsorption onto modified vermiculite. Appl. Clay Sci. 2006, 32, 261-270. [CrossRef]

67. Dultz, S.; Riebe, B.; Bunnenberg, C. Temperature effects on iodine adsorption on organo-clay minerals II. Structural effects. Appl. Clay Sci. 2005, 28, 17-30. [CrossRef]

68. Wei, S.Y.; Deng, X.H. Surface charge and adsorption characteristics for fluoride of hexadecyltrimethylammonium modified vermiculite. Adv. Mater. Res. 2013, 781-784, 2265-2268. [CrossRef]

69. Matusik, J.; Klapyta, Z. Characterization of kaolinite intercalation compounds with benzylalkylammonium chlorides using XRD, TGA/DTA and CHNS elemental analysis. Appl. Clay Sci. 2013, 83-84, 433-440. [CrossRef]

70. Lee, S.Y.; Kim, S.J. Delamination behavior of silicate layers by adsorption of cationic surfactants. J. Colloid Interface Sci. 2002, 248, 231-238. [CrossRef]

71. Hu, Z.W.; He, G.H.; Liu, Y.F.; Dong, C.X.; Wu, X.M.; Zhao, W. Effects of surfactant concentration on alkyl chain arrangements in dry and swollen organic montmorillonite. Appl. Clay Sci. 2013, 75-76, 134-140. [CrossRef]

72. Gammoudi, S.; Frini-Srasra, N.; Srasra, E. Influence of exchangeable cation of smectite on HDTMA adsorption: Equilibrium, kinetic and thermodynamic studies. Appl. Clay Sci. 2012, 69, 99-107. [CrossRef]

73. Bartelt-Hunt, S.L.; Burns, S.E.; Smith, J.A. Nonionic organic solute sorption onto two organobentonites as a function of organic-carbon content. J. Colloid Interface Sci. 2003, 266, 251-258. [CrossRef]

74. Yu, X.B.; Wei, C.H.; Ke, L.; Hu, Y.; Xie, X.Q.; Wu, H.Z. Development of organovermiculite-based adsorbent for removing anionic dye from aqueous solution. J. Hazard. Mater. 2010, 180, 499-507. [CrossRef]

75. Thanos, A.G.; Sotiropoulos, A.; Malamis, S.; Katsou, E.; Pavlatou, E.A.; Haralambous, K.J. Regeneration of HDTMA-modified minerals after sorption with chromate anions. Desalin. Water Treat. 2016, 57, 27869-27878. [CrossRef]

76. Manning, B.A.; Goldberg, S. Modeling arsenate competitive adsorption on kaolinite, montmorillonite and illite. Clays Clay Miner. 1996, 44, 609-623. [CrossRef]

77. Abollino, O.; Giacomino, A.; Malandrino, M.; Mentasti, E. Interaction of metal ions with montmorillonite and vermiculite. Appl. Clay Sci. 2008, 38, 227-236. [CrossRef] 
78. Dos Anjos, V.E.; Rohwedder, J.R.; Cadore, S.; Abate, G.; Grassi, M.T. Montmorillonite and vermiculite as solid phases for the preconcentration of trace elements in natural waters: Adsorption and desorption studies of As, Ba, Cu, Cd, Co, Cr, Mn, Ni, Pb, Sr, V, and Zn. Appl. Clay Sci. 2014, 99, 289-296. [CrossRef]

79. Smedley, P.L.; Kinniburgh, D.G. A review of the source, behaviour and distribution of arsenic in natural waters. Appl. Geochem. 2002, 17, 517-568. [CrossRef]

80. Ben Issa, N.; Rajakovic-Ognjanovic, V.N.; Jovanovic, B.M.; Rajakovic, L.V. Determination of inorganic arsenic species in natural waters-Benefits of separation and preconcentration on ion exchange and hybrid resins. Anal. Chim. Acta 2010, 673, 185-193. [CrossRef]

81. Zhang, Z.B.; Li, J.X.; Sun, C.Z.; Marhaba, T.F.; Zhang, W.; Zhang, Y.H. Arsenic Speciation by Sequential Extraction from As-Fe Precipitates Formed Under Different Coagulation Conditions. Water Air Soil Pollut. 2016, 227, 9. [CrossRef]

82. Yusof, A.M.; Malek, N. Removal of $\mathrm{Cr}(\mathrm{VI})$ and $\mathrm{As}(\mathrm{V})$ from aqueous solutions by HDTMA-modified zeolite $\mathrm{Y}$. J. Hazard. Mater. 2009, 162, 1019-1024. [CrossRef]

83. Sposito, G.; Skipper, N.T.; Sutton, R.; Park, S.H.; Soper, A.K.; Greathouse, J.A. Surface geochemistry of the clay minerals. Proc. Natl. Acad. Sci. USA 1999, 96, 3358-3364. [CrossRef]

84. Wainipee, W.; Cuadros, J.; Sephton, M.A.; Unsworth, C.; Gill, M.G.; Strekopytov, S.; Weiss, D.J. The effects of oil on As (V) adsorption on illite, kaolinite, montmorillonite and chlorite. Geochim. Cosmochim. Acta 2013, 121, 487-502. [CrossRef]

85. Mohapatra, D.; Mishra, D.; Chaudhury, G.R.; Das, R.P. Arsenic adsorption mechanism on clay minerals and its dependence on temperature. Korean J. Chem. Eng. 2007, 24, 426-430. [CrossRef]

86. Greenleaf, J.E.; Cumbal, L.; Staina, I.; SenGupta, A.K. Abiotic As(III) oxidation by hydrated Fe(III) oxide (HFO) microparticles in a plug flow columnar configuration. Process Saf. Environ. Prot. 2003, 81, 87-98. [CrossRef]

87. Raczyński, W.W. Zarys Teorii Dynamiki Sorpcji i Chromatografii, 1st ed.; Wydawnictwo Naukowo-Techniczne Warszawa: Warszawa, Poland, 1966.

88. Maślankiewicz, K.; Szymański, A. Mineralogia Stosowana; Wydawnictwo Geologiczne: Warszawa, Poland, 1976; p. 464.

(C) 2019 by the authors. Licensee MDPI, Basel, Switzerland. This article is an open access article distributed under the terms and conditions of the Creative Commons Attribution (CC BY) license (http://creativecommons.org/licenses/by/4.0/). 